\title{
Type A Francisella tularensis Acid Phosphatases Contribute to Pathogenesis
}

\author{
Nrusingh P. Mohapatra, Shilpa Soni, Murugesan V. S. Rajaram, Kristi L. Strandberg, John S. Gunn*
}

Department of Microbial Infection and Immunity, Center for Microbial Interface Biology, The Ohio State University, Columbus, Ohio, United States of America

\begin{abstract}
Different Francisella spp. produce five or six predicted acid phosphatases (AcpA, AcpB, AcpC, AcpD, HapA and HapB). The genes encoding the histidine acid phosphatases (hapA, hapB) and $a c p D$ of $F$. tularensis subsp. Schu S4 strain are truncated or disrupted. However, deletion of HapA (FTT1064) in F. tularensis Schu S4 resulted in a 33\% reduction in acid phosphatase activity and loss of the four functional acid phosphatases in $F$. tularensis Schu $\mathrm{S} 4(\triangle \mathrm{ABCH})$ resulted in a $>99 \%$ reduction in acid phosphatase activity compared to the wild type strain. All single, double and triple mutants tested, demonstrated a moderate decrease in mouse virulence and survival and growth within human and murine phagocytes, whereas the $\triangle \mathrm{ABCH}$ mutant showed $>3.5$-fold decrease in intramacrophage survival and $100 \%$ attenuation of virulence in mouse. While the Schu S4 $\triangle \mathrm{ABCH}$ strain was attenuated in the mouse model, it showed only limited protection against wild type challenge. $F$. tularensis Schu S4 failed to stimulate reactive oxygen species production in phagocytes, whereas infection by the $\triangle \mathrm{ABCH}$ strain stimulated 5- and 56-fold increase in reactive oxygen species production in neutrophils and human monocyte-derived macrophages, respectively. The $\triangle \mathrm{ABCH}$ mutant but not the wild type strain strongly co-localized with $\mathrm{p} 47^{\text {phox }}$ and replicated in macrophages isolated from $\mathrm{p} 47^{\text {phox }}$ knockout mice. Thus, F. tularensis Schu S4 acid phosphatases, including the truncated HapA, play a major role in intramacrophage survival and virulence of this human pathogen.
\end{abstract}

Citation: Mohapatra NP, Soni S, Rajaram MVS, Strandberg KL, Gunn JS (2013) Type A Francisella tularensis Acid Phosphatases Contribute to Pathogenesis. PLoS ONE 8(2): e56834. doi:10.1371/journal.pone.0056834

Editor: Alain Charbit, Université Paris Descartes; INSERM, U1002, France

Received October 6, 2012; Accepted January 15, 2013; Published February 15, 2013

Copyright: $\odot 2013$ Mohapatra et al. This is an open-access article distributed under the terms of the Creative Commons Attribution License, which permits unrestricted use, distribution, and reproduction in any medium, provided the original author and source are credited.

Funding: This work was sponsored by the NIH/NIAID Regional Center of Excellence for Bio-defense and Emerging Infectious Diseases Research (RCE) Program. The authors wish to acknowledge membership within and support from the Region V "Great Lakes" RCE (NIH award 2-U54-Al-057153). The funders had no role in study design, data collection and analysis, decision to publish, or preparation of the manuscript.

Competing Interests: The authors have declared that no competing interests exist.

*E-mail: gunn.43@osu.edu

\section{Introduction}

Tularemia is a potentially fatal systemic disease of humans and animals caused by the bacterial pathogen Francisella tularensis subsp. tularensis ( $F$. tularensis). The disease can be transmitted by ticks, biting flies, mosquitoes, water exposure, food, or aerosols and primarily occurs in the northern hemisphere including North America, Europe, and Asia. Small mammals (particularly rabbits) act as a reservoir for this bacterium $F$. tularensis is a facultative intracellular pathogen of macrophages and neutrophils, as well as nonphagocytic cells such as hepatocytes and airway epithelial cells [1-6]. Tularemia in humans is an acute febrile disease that shows cutaneous, oculoglandular, pneumonic, gastrointestinal or septic features depending upon the route of infection [7-10]. Only two of the four subspecies of Francisella tularensis (subsp. tularensis, holarctica) cause significant disease in immuno-competent humans. Infections with Type A F. tularensis are associated with the highest mortality rates. All Francisella subspecies exhibit greater than 95\% DNA identity [11]. An attenuated live vaccine strain (LVS) of $F$. holarctica was isolated and has been used extensively in humans, but has not achieved approval for use in the United States [12].

Less than $10 \mathrm{CFU}$ of a Type A strain is sufficient to cause the pneumonic form of tularemia in humans. This is characterized by rapid multiplication inside the cytosol of infected cells and subsequent damage to host tissues and organs, thereby disrupting their normal functions and inducing host cellular inflammatory responses [13]. F. tularensis enters the host macrophage by an asymmetric pseudo loop that is dependent upon serum complement and host cell receptors [14-18]. Once the bacterium is inside the host cell, it arrests phagosome maturation and the bacterialcontaining vacuole transiently acidifies, which leads to the escape of the bacterium into the cytosol of the macrophage [19-21]. At later stages of cellular infection, the bacterium can be found in vesicles that are likely related to autophagy [22,23]. Bacterial release from the host cells is thought to occur following Francisellainduced apoptosis [24-27] and pyroptosis [28,29]. However, the complete intracellular life cycle of $F$. tularensis is not clearly understood.

Very few virulence factors have been identified in Francisella and the molecular events accounting for the development of tularemia are unclear. Several studies have indicated that the products of the Francisella pathogenicity island (FPI) genes either directly or indirectly contribute to the virulence of this pathogen [30-35]. Regulation of the FPI is controlled by several global regulators including MglA, SspA, PmrA, FevR, Hfq, RipA and MigR [3647]. In addition to the FPI genes, Francisella acid phosphatases have been shown to play a key role in several virulence related properties $[23,48,49]$. The published genome sequence of $F$. tularensis Schu S4 possesses six acid phosphatases $(a c p A, a c p B$, acpC and truncated $a c p D, h a p A$, and $h a p B$ ) [50]. Acid phosphatases are ubiquitous in nature, hydrolyze phosphomonoesters at acidic $\mathrm{pH}$ and have been associated with pathogen survival inside the phagosome through the inhibition of respiratory burst [51-58]. In our previous studies, we observed that the combined deletion of 
AcpA with AcpB, AcpC and HapA in F. novicida resulted an attenuated strain that was $100 \%$ protective against homologous challenge in the mouse model. Additionally this mutant did not escape from the macrophage phagosome, had negligible phosphatase activity, and failed to suppress the oxidative burst in human phagocytes $[23,49]$. Transcriptional analysis demonstrated that expression of $a c p A$ and hapA increased at initial stage of the macrophage infection [23], and an in vivo proteomic analysis of Francisella infected mice spleens showed that there was 2-fold more AcpA protein isolated from these organs compared to the bacteria grown in broth [59]. Pierson et al. observed that $F$. novicida and $F$. philomiragia form outer membrane vesicles and these vesicles carry several hundred proteins, with AcpA one of the major proteins present [60]. A comparative proteomic profiling of culture filtrates of various Francisella spp. showed that all secreted AcpA in vitro [61]. Furthermore, a recent study performed by Dai et al. demonstrated that Francisella spp. AcpA is secreted into the culture supernatant in vitro and also secreted and translocated across the phagosomal membrane into the host cell cytosol at early stages of $F$. novicida and $F$. tularensis Schu S4 infection [62]. In this study, deletion of AcpA, AcpB, AcpC and truncated HapA in F. tularensis Schu S4 resulted loss of more than $99 \%$ of the acid phosphatase activity, more than a 3-log decrease in survival and growth inside human and murine macrophages and attenuation in the mouse model. Additionally we examined ROS induction by this mutant and demonstrated that it co-localized with NADPH oxidase components in human neutrophils and monocyte derived macrophages and lacked the wild type strain's ability to suppress the oxidative burst.

\section{Materials and Methods}

\section{Growth conditions, strains and plasmid construction}

All experiments were performed in Modified Mueller Hinton media (MMH): Mueller-Hinton medium supplemented with $0.1 \%$ glucose, $0.025 \%$ ferric pyrophosphate and $2 \%$ IsoVitaleX (Becton Dickinson, Cockeysville, MD) or on CHOC II plates incubated at $37^{\circ} \mathrm{C}$ and $5 \% \mathrm{CO}_{2}$. Kanamycin was added at a concentration of at $15 \mathrm{mg} / \mathrm{L}$ when required. Primers, bacterial strains and plasmids are described in Table 1. The Type A virulent strain, F. tularensis subsp. tularensis Schu S4 was obtained from Rick Lyons (University of New Mexico, Albuquerque, USA). Schu S4 infections were conducted by CDC approved select agent users in facilities at The Ohio State University in accordance with local and national biosafety plans and procedures.

The suicide vector pJC84 (generously provided by Jean Celli, Rocky Mountain Laboratories, NIAID, NIH, Hamilton, MT, USA) was used to generate in-frame deletions of acid phosphatase genes in the $F$. tularensis Schu S4 strain. Deletion constructs of $a c p A$ (FTT0221), $a c p B$ (FTT0156), $a c p C$ (FTT0620) and hapA (FTT1064) were constructed as described by Wehrley et al. [63]. In brief, the $\sim 1100$ bp upstream and downstream products of the gene of interest were PCR amplified and cloned into the pJC84 plasmid using suitable restriction sites. The details of the primers are described in Table 1. All plasmid constructs were verified by sequencing and glycerol stocks were frozen at $-80^{\circ} \mathrm{C}$ for further use. The deletion constructs were transformed into Schu S4 by electroporation as described by McRae et al. [64]. The kanamycin-resistant transformants were tested for integration of the allelic replacement plasmid using primer combinations JG2169/2170 and JG2171/2172. The positive clones were subjected to sucrose counter selection as described earlier [64]. Sucrose-resistant clones were patched on MMH-kanamycin plates to verify loss of the kanamycin-resistance marker, and colony PCR was performed to detect clones with allelic replacement within the correct chromosomal locus, using primers JG1795/JG1798 and primers JG2007/JG2008 for the acpA deletion, primers JG1827/ JG1830 and primers JG2171/2172 for the $a c p B$ deletion, primers JG1831/JG1834 and primers JG2171/2172 for the acpC deletion, and primers JG1839/JG1842 and primers JG2009/JG2010 for the hapA deletion. The genetic complementations of acpA and/or hapA were constructed in pFNLTP6-GroEL plasmid as described by Wehrley et al. [63]. In Brief, acpA and hapA genes were amplified from Schu S4 genomic DNA using the primer sets JG2007/2008 and JG2009/2010, respectively. The acpA amplified PCR product was cloned into an EcoRI/XhoI digested pFNLTP6-GroEL plasmid (pFNLTP-6-AcpA) and/or the hapA PCR product was cloned into XhoI/BamHI digested pFNLTP6GroEL plasmid (pFNLTP6-HapA/pFLNLTP6-AcpA-Hap). The cloned plasmids were confirmed by sequencing and transformed into different strains by electroporation as described above [63]

\section{Acid phosphatase assay}

Acid phosphatase activity of Schu S4 and the deletion mutants were measured essentially as described previously [23]. The strains were grown overnight in $3 \mathrm{ml}$ of $\mathrm{MMH}$ broth, cultures were normalized and cells were pelleted by centrifugation at $8000 \times \mathrm{g}$ and $4^{\circ} \mathrm{C}$ for $15 \mathrm{~min}$. The cell pellets were washed with phosphate buffer saline (PBS) and resuspended in $1 \mathrm{ml}$ of PBS and transferred into the $2 \mathrm{ml}$ lysing matrix (1 micron beads) tubes and vortexed for 5 cycles of $2 \mathrm{~min}$ each. Tubes were placed in ice between each cycle. Lysates were collected and centrifuged at $8000 \times \mathrm{g}$ and $4^{\circ} \mathrm{C}$ for $15 \mathrm{~min}$ to remove any unbroken cell debris. The total protein concentration of the samples was measured by the BCA protein assay kit (Thermo Fisher Scientific Inc., Waltham, MA), the protein content was normalized before measuring acid phosphatase activity. The acid phosphatase activity was measured using the 6,8-difluoro-4-methylumbelliferyl phosphate (DiFMUP, Invitrogen) substrate. $50 \mu \mathrm{L}$ of the $200 \mu \mathrm{M}$ DiFMUP working solution was added into $50 \mu \mathrm{l}$ of sample or control and the reaction was incubated at room temperature for $10 \mathrm{~min}$. The mean fluorescence unit of the samples and the control was determined by an ELISA reader setting of excitation at $\sim 360 \mathrm{~nm}$ and emission detection at $\sim 460 \mathrm{~nm}$. The relative fluorescence unit (RFU) was converted into percentages of the phosphatase activity measured for the wild type strain.

\section{Intramacrophage survival assay}

Murine alveolar J774.1 macrophages, phorbol myristate acetate-induced (PMA, $10 \mathrm{ng} / \mathrm{ml}$ ) THP-1 macrophages, primary murine bone marrow-derived macrophages (BMDMs), human monocyte derived macrophages (hMDMs) and neutrophils were used to study the intracellular survival of $F$. tularensis $\mathrm{Schu} \mathrm{S} 4$ and the Schu S4 acid phosphatase mutants. Murine bone marrow cells were isolated from femurs of 6- tol0-week-old BALB/c (Harlan Sprague), C57BL/ 6 and congenic $\mathrm{p} 47^{\text {phox }}$ knockout mice (provided by Dr. Chandan Sen, The Ohio State University). In brief, bone marrow-derived macrophages were cultured in Iscove's Modified Dulbecco's Media (IMDM) containing 10\% heat-inactivated FBS, $20 \% \mathrm{~L}$ cell-conditioned medium, $100 \mathrm{U} / \mathrm{ml}$ penicillin, and $100 \mu \mathrm{g} / \mathrm{ml}$ streptomycin at $37^{\circ} \mathrm{C}$ in a humidified atmosphere containing $5 \% \mathrm{CO}_{2}$. After 5 days of incubation, cells were collected and plated in 24-well plates in IMDM containing $10 \%$ heat-inactivated FBS [49]. Using The Ohio State University Institutional Review Board approved protocol, heparinized blood samples were collected from healthy human donors and processed further to isolate the hMDMs and neutrophils as described by Mohapatra et al. [49]. 
Regarding in vitro infections, $2 \times 10^{5} \mathrm{~J} 774.1$ macrophages, PMA induced THP-1 macrophages or primary BMDMs were seeded in 24-well tissue culture plates. The macrophage monolayers were infected with $F$. tularensis wild type Schu S4 and acid phosphatase mutants grown over night in MMH media at an MOI 50:1 as described previously [49]. At various time points, macrophages were lysed with $0.05 \%$ SDS and plated on CHOC II plates to enumerate the colony forming units (CFU).

For phagocyte infection studies in hMDMs and neutrophils, Francisella strains were opsonized with $50 \%$ autologous serum for $30 \mathrm{~min}$ at $37^{\circ} \mathrm{C}$ and subsequently washed three times with defined (HBSS) buffer to remove excess serum. Opsonized Francisella were resuspended in appropriate buffer and kept on ice. Human MDMs and PMNs were infected with opsonized bacteria at an MOI $\sim 50: 1$ and the intracellular survival of the bacterial strains were determined as described by Mohapatra et al. [49].

\section{Mouse virulence studies}

Pathogen free, 6-8 week old female BALB/c mice ( $\mathrm{n}=5$ /group) were purchased from Harlan Sprague. Mice were housed in sterile micro isolator cages in the BSL-3 facility at The Ohio State University. Mice were housed and used in strict accordance with guidelines established by The Ohio State University Institutional Animal Care and Use Committee (IACUG), and all efforts were made to minimize animal suffering. The mice were anesthetized intra-peritoneally with $200 \mu \mathrm{l}$ tribromoethanol anesthesia $(2.5 \mathrm{gm}$ 2,2,2-tribromoethanol, $5 \mathrm{ml}$ 2-methyl-2butanol, $200 \mathrm{ml}$ water), infected with wild type $F$. tularensis $\mathrm{Schu} \mathrm{S} 4$ or the mutant strains via the intranasal route $(25 \mu \mathrm{l}$ of bacteria in PBS in the nares of each mouse, $3 \times 10^{3}$ CFU total) for survival and vaccine studies. Animals were monitored twice daily for signs of morbidity. Lungs and spleens were collected from the infected mice at different time points and homogenized in sterile PBS to determine the bacterial burden. Bacterial colony counts in each organ were determined after $48 \mathrm{~h}$ of incubation at $37^{\circ} \mathrm{C}$ from the homogenate organs on CHOG II plates.

\section{Transmission electron microscopy}

PMA-induced THP-1 macrophages were infected with wild type Schu S4 or the quadruple mutant at an MOI of 50:1 in fourwell chamber slides. At 30 min or two hours post-infection, wells were washed three times with PBS, and fresh medium containing $50 \mu \mathrm{g} / \mathrm{ml}$ gentamicin was added for $30 \mathrm{~min}$. After gentamicin treatment, cells were washed three times with PBS and either fixed or incubated further in the presence of medium containing $10 \mu \mathrm{g} /$ $\mathrm{ml}$ gentamicin for an additional $22 \mathrm{hr}$. At the chosen time points, the wells were washed and fixed immediately with $2.5 \%$ warm glutaraldehyde followed by a cocktail of $2.5 \%$ glutaraldehyde and $1 \%$ osmium tetroxide in $0.1 \mathrm{M}$ sodium cacodylate $(\mathrm{pH} 7.3)$ for $15 \mathrm{~min}$. The cells were then stained with $0.25 \%$ uranyl acetate in $0.1 \mathrm{M}$ sodium acetate buffer $(\mathrm{pH}$ 6.3) for $45 \mathrm{~min}$, and viewed by transmission electron microscopy using an FEI Technai G2 Spirit microscope at $60 \mathrm{kV}$. The intra-phagosomal or cytosolic bacteria were identified as described by Mohapatra et al. [23].

\section{Respiratory burst assays}

Production of reactive oxygen species by human neutrophils and macrophages after Francisella infection was detected using a luminescent substrate in an ELISA reader as described previously [49]. Human serum-opsonized zymosan particles (MOI of 10:1) and PMA (200 nM) were used as positive controls for ROS production. The inhibition of ROS production by Francisella spp. was tested by incubating phagocytes with $F$. tularensis for $10 \mathrm{~min}$ at $37^{\circ} \mathrm{C}$ prior to adding opsonized zymosan.

\section{Confocal microscopy}

The co-localization of Francisella with the NADPH oxidase components in human neutrophils and hMDMs were detected by confocal microscopy as described by Mohapatra et al. [49]. Neutrophils $\left(10^{6} /\right.$ well $)$ on serum-coated coverslips were infected with serum-opsonized Francisella spp. At different time intervals, coverslips were washed with HBSS and fixed with $3.5 \%$ paraformaldehyde for $30 \mathrm{~min}$ [49]. After fixation, cells were washed and permeabilized with chilled methanol for $15 \mathrm{sec}$ followed by HBSS washing and blocking with 20\% normal human serum (Cambrex, Charles City, IA) and 5\% BSA (blocking solution) for $2 \mathrm{hrs}$. Infected cells were treated with a primary antibody: mouse monoclonal anti- $F$. tularensis (1:5000 dilution; BEI Resource) and/or rabbit anti-p47 $7^{\text {phox }} \mathrm{Ab}$ or rabbit anti-gp91 ${ }^{\text {phox }} \mathrm{Ab}$ (1:5000 dilution; Santacruz Biotech, CA) for $2 \mathrm{hrs}$ in blocking solution. Coverslips were washed and incubated with secondary $\mathrm{Ab}$ (goat anti-mouse Alexa Fluor 488 or donkey anti-rabbit Alexa Fluor 546, 1:5000 dilution [Invitrogen]) for $1 \mathrm{hr}$. Coverslips were washed and mounted with Prolong anti-fade reagent (Invitrogen) and viewed with Olympus FV1000 spectral confocal microscope. Resting neutrophils or cells activated with $200 \mathrm{nM}$ PMA for 5 min were used as negative and positive controls, respectively. Similarly, human MDMs were used to determine the co-localization of the bacterium with $\mathrm{p} 47^{\text {phox }} / \mathrm{gp} 91^{\text {phox }}$ by confocal microscopy as described previously [49]. Quantification of co-localization of the bacteria with the NADPH oxidase components was determined as described by Mohapatra et al. [49].

The phosphorylation of $\mathrm{p} 40^{\text {phox }}$ and $\mathrm{p} 47^{\text {phox }}$ in cell lysates of human neutrophils and MDMs was detected as described previously by Mohapatra et al. [49]. In brief, neutrophils or hMDMs were infected with serum-opsonized Schu S4 strains at an MOI $\sim 50: 1$ and the infection was synchronized by a brief incubation at $12^{\circ} \mathrm{C}$. At different time intervals, uninfected and infected cells were lysed in macrophage lysis buffer. The cell lysates were boiled in Laemmli sample buffer, and equal amounts of proteins were separated by SDS-PAGE, transferred to a nitrocellulose membrane, and incubated with primary $\mathrm{Ab}$ against phospho-p40 ${ }^{\text {phox }}$ (Cell Signaling Technology, Beverly, MA; 1:500 dilution) or phospho-p $47^{\text {phox }}$ (1:1000 dilution) (Dang, 2006). This was followed by a goat anti-rabbit HRP-conjugated secondary Ab (Bio-Rad; 1:1000 dilution) and development by ECL (Amersham/ GE Healthcare Bio-Sciences, Piscataway, NJ). The ECL signal was quantified using a scanner and densitometry (Scion Image, Frederick, MD), as previously described [65].

\section{Results}

\section{Construction of $F$. tularensis Schu S4 acid phosphatase gene deletions}

The comparative genome analysis of $F$. novicida and $F$. tularensis subsp. tularensis revealed that AcpA (FTT0221), AcpB (FTT0156) and AcpC (FTT0620) were highly conserved (98.05, 98.97, and 96.76\% identity, respectively). The genes encoding HapA, HapB, and AcpD are truncated/interrupted in F. tularensis subsp. tularensis $\mathrm{Schu} \mathrm{S} 4$. This truncation has resulted in a lack of interest in HapA in Schu S4, driven by the fact that the predicted active site is in the C-terminal region that would be absent in the Schu S4 truncated protein. $a c p D$ and $h a p B$ are severely disrupted in Schu S4 [50] and thus were not further considered. In-frame deletion of genes creating single $(\triangle a c p A, \Delta a c p B, \Delta a c p C, \triangle h a p A)$, double $[\triangle a c p A \triangle a c p C$ ( $\triangle \mathrm{AC}), \triangle a c p B \triangle a c p C(\triangle \mathrm{BC}), \triangle a c p A, \triangle a c p B(\triangle \mathrm{AB}), \triangle a c p A \Delta h a p A$ $(\triangle \mathrm{AH}), \triangle a c p B \quad \triangle h a p A(\Delta \mathrm{BH}), \triangle \operatorname{acp} C \Delta h a p A(\Delta \mathrm{CH})]$, triple $[\Delta a c p A$

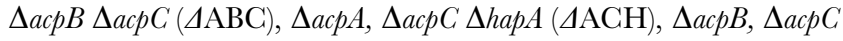
$\triangle h a p A(\triangle \mathrm{BCH})]$ and quadruple [ $\triangle$ acpA $\triangle$ acpB $\triangle$ acpC AhapA 
Table 1. List of primers, strains and plasmids.

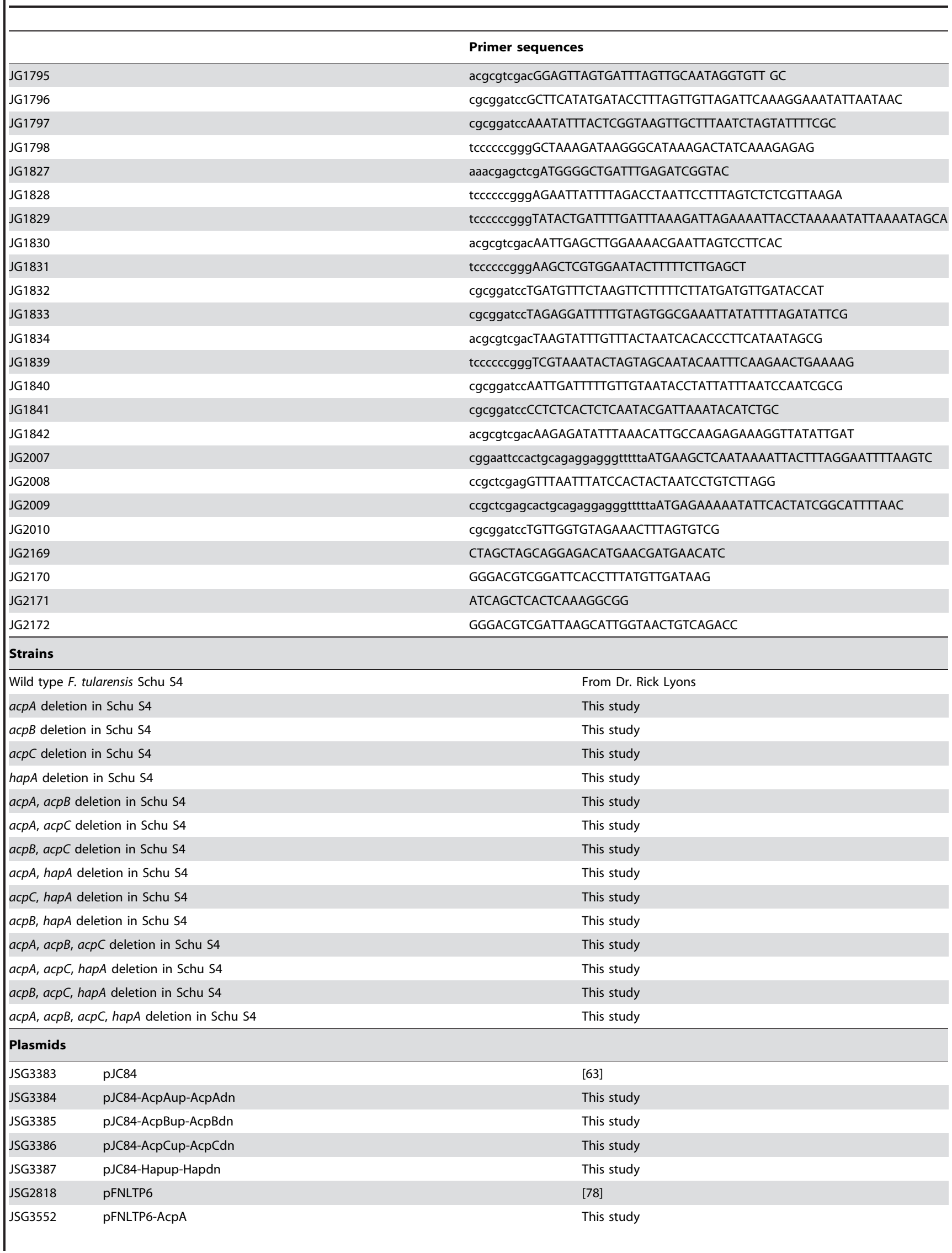


Table 1. Cont.

\begin{tabular}{lll}
\hline & & \\
\hline Plasmids & \\
\hline JSG3553 $\quad$ pFNLTP6-Hap & This study \\
JSG3554 pFNLTP6-AcPA-Hap & This study \\
\hline doi:10.1371/journal.pone.0056834.t001 &
\end{tabular}

$(\triangle A B C H)]$ mutants in Schu S4 were generated using the SacBassisted allelic replacement suicide vector pJC84, as described by Wherly et al. [63]. The lack of polar effects of the downstream genes of AcpC mutant was determined by RT-PCR (data not shown). Polar effects were not a concern for the other mutants based on their genomic arrangement. None of the constructed mutants demonstrated a growth defect in $\mathrm{MMH}$ broth or abnormal colony size/appearance on plates (data not shown).

\section{Acid phosphatase activity assays of mutant and wild type strains}

To examine their individual and additive contributions to Schu S4 acid phosphatase activity, strains lacking AcpA, AcpB, AcpC and HapA were examined. The enzyme activities were determined from the whole cell lysates by measuring the RFU, using difluoromethyl umbeliferyl phosphate (DifMUP) as the substrate. The RFU were displayed as a percentage of enzyme activity compared to the wild type strain (Fig. 1). Deletion of acpA or hapA decreased the total acid phosphatase activity by $89 \%$ and $33 \%$ respectively compared to the wild type strain. The reduction in acid phosphatase activity by deletion of hapA was surprising as this gene was predicted to produce a non-functional protein. The loss of $a c p B$ or $a c p C$ contributed $11 \%$ and $43 \%$ of the acid phosphatase activity respectively (data not shown). In triple deletion strains, we found that $93 \%$ and $95 \%$ of acid phosphatase activity was decreased in $\triangle \mathrm{ABC}$ and $\triangle \mathrm{ACH}$ mutants, respectively, compared to wild type strain. Acid phosphatase activity was completely abrogated in a $\triangle \mathrm{ABCH}$ mutant $(>99.99 \%)$. The acid phosphatase activity of the $\triangle \mathrm{ABCH}$ mutant complemented with acpA or hapA or both genes recovered to 79,38 and $88 \%$ of wild type enzyme activity, respectively (Fig. 1).

\section{Intramacrophage survival of acid phosphatase mutants}

Macrophages are the primary targets of the $F$. tularensis infection in mammals, and our previous study demonstrated that $F$. novicida acid phosphatases contribute to survival in human and murine macrophages [23,48]. To determine if the Schu S4 acid phosphatase mutants similarly contribute to growth and survival in human and murine macrophages, we infected these phagocytes with various acid phosphatase mutants and the bacterial CFU were determined from $15 \mathrm{~min}$ to $24 \mathrm{hrs}$ post-infection. The $\triangle a c p A$ and $\triangle h a p A$ mutant showed $>1 \log$ reduction in CFU compared to the wild type macrophages at $24 \mathrm{hrs}$ post infection in hMDMs, the human macrophage-like cell line THP-1, BMDMs (from BALB/ c), and J774.1 mouse macrophage cell line (Fig. 2A-D). The $\triangle \mathrm{ABCH}$ mutant exhibited a $3-4 \log$ decrease in the number of $\mathrm{CFU}$ at $24 \mathrm{hrs}$ post infection in all macrophages examined, while $\triangle \mathrm{ABC}$ and $\triangle \mathrm{ACH}$ mutants showed a $>2$ log decrease in the number of CFU at $24 \mathrm{hrs}$ post infection. The mutant and wild type strains showed similar cell association and uptake as determined by confocal microscopy (data not shown). Complementation of the $\triangle \mathrm{ABCH}$ mutant with $\mathrm{pAcpA}$ and/or $\mathrm{pHapA}$ regained the majority of the ability to survive and replicate in all macrophages examined $(<1 \log$ reduction in $\mathrm{CFU}$ recovered at $24 \mathrm{hrs}$ postinfection, data not shown).

We also investigated the survival of the Schu S4 acid phosphatase mutants in human neutrophils at $15 \mathrm{~min}$ to $120 \mathrm{~min}$ post infection (Fig. 2E). Survival in these cells showed a similar pattern to the survival observed in macrophages, with the $\triangle \mathrm{ABCH}$ mutant having a severe survival defect and the $\triangle a c p A$ and $\Delta$ hapA showing intermediate survival defects (Fig. 2E). Additionally, these differences could also be observed at the earliest time point of $15 \mathrm{~min}$ in these cells (versus a similar time point in hMDMs) likely due to the increased antimicrobial action of human neutrophils vs. human macrophages.

\section{Mouse virulence analysis}

To determine if any of the acid phosphatase mutants exhibit virulence defects in the mouse model of tularemia, 6-8 week old female $\mathrm{BALB} / \mathrm{c}$ mice $(\mathrm{n}=5)$ were infected with $\Delta a c p A, \Delta a c p B$, $\Delta a c p C, \Delta h a p A, \Delta \mathrm{AH}, \Delta \mathrm{CH}, \Delta \mathrm{ABC}, \Delta \mathrm{ACH}$, or $\triangle \mathrm{ABCH}(\mathrm{n}=20$ for $\triangle \mathrm{ABCH}$ ) and wild type Schu $\mathrm{S} 4$ strains by the intranasal route at a dose of $\sim 3 \times 10^{3}$ CFU. Wild type, $\triangle a c p A, \Delta a c p B, \triangle a c p C, \Delta$ hapA, $\triangle \mathrm{AH}, \Delta \mathrm{CH}$ and $\triangle \mathrm{ABC}$ infected mice died within 2-12 days after infection, with wild type mice succumbing first, followed by the single deletions and then the double/triple deletions (Fig. 3A). However, all mice infected with the $\triangle \mathrm{ABCH}$ mutant all survived for 6 weeks after infection. When a dose of $10^{6} \mathrm{CFU}$ was used, mice of all strains tested died rapidly except those infected with the $\triangle \mathrm{ABCH}$ strain, which showed $70 \%$ survival (data not shown). To further investigate the mouse virulence studies, we collected the

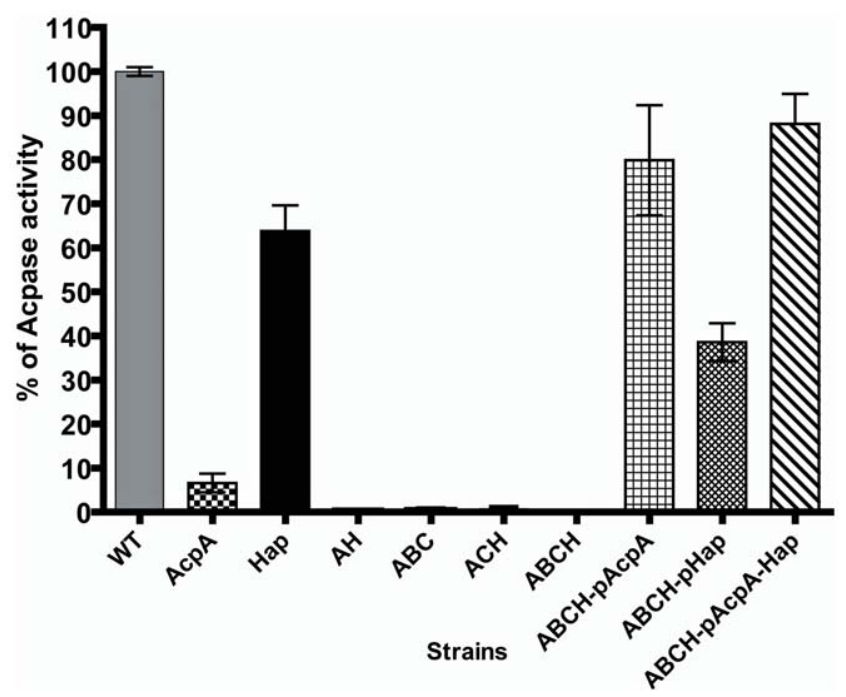

Figure 1. Acid phosphatase assay. Acid phosphatase activity was determined from whole cell lysates of $F$. tularensis acid phosphatase mutants by a fluorometric method using DiF-MUP as the substrate. The data are presented as percent of wild type phosphatase activity. doi:10.1371/journal.pone.0056834.g001 
A.

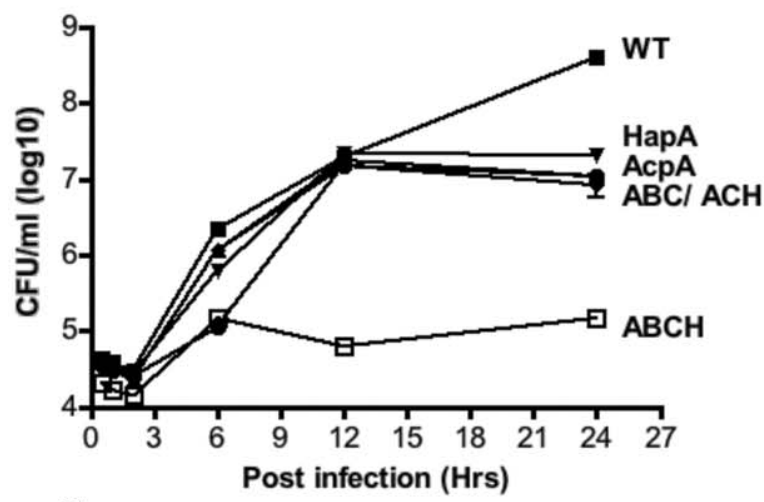

C.

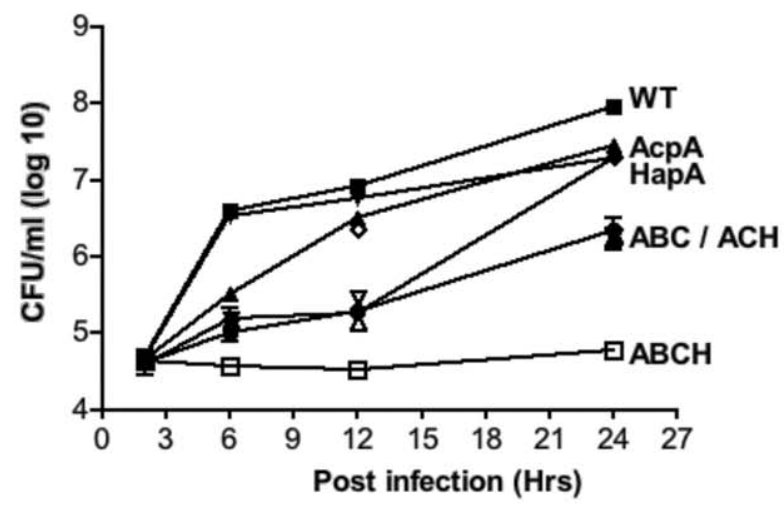

E.

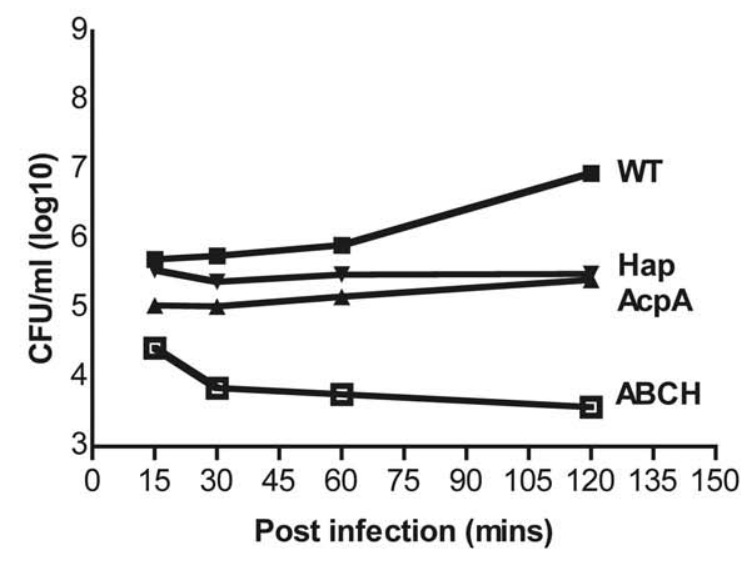

B.

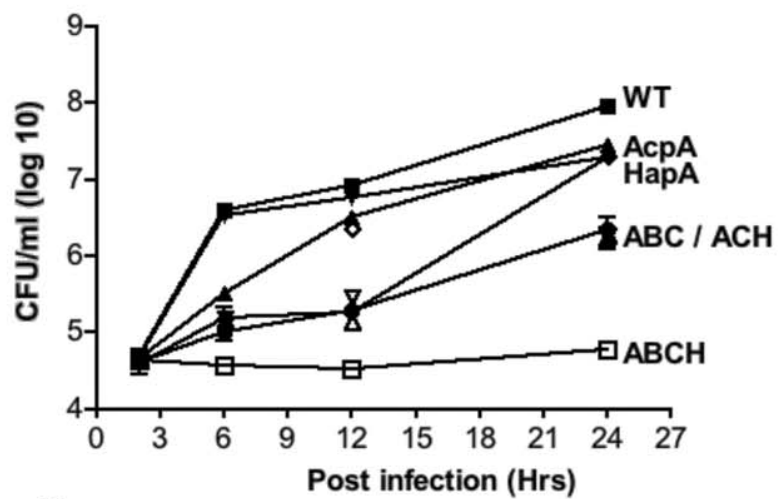

D.

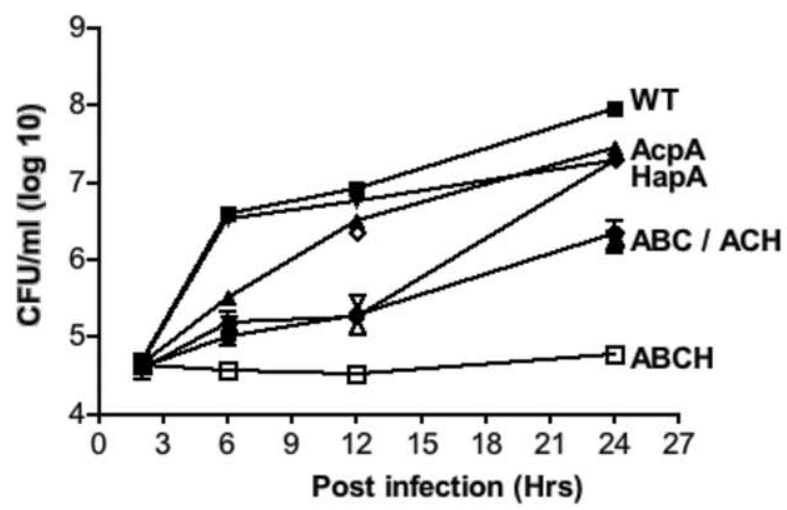

Figure 2. Intramacrophage survival of $F$. tularensis Schu S4 wild type and the acid phosphatase mutants in human and murine macrophages. (A) hMDMs, (B) PMA induced THP-1 macrophages, (C) bone marrow derived macrophages from wild type BALB/c mice, (D) J774.1

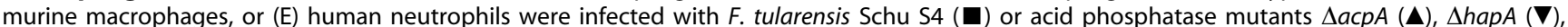
$\triangle \mathrm{ABC}(\checkmark), \triangle \mathrm{ACH}(\mathbf{)})$, or $\triangle \mathrm{ABCH}(\square)$ strains.

doi:10.1371/journal.pone.0056834.g002

liver and spleen of the infected mice and determined their bacterial load. As expected, a high bacterial burden $\left(>10^{7} \mathrm{CFU}\right)$ in the liver and spleen of the mouse was correlated with death in all tested strains (data not shown).

To determine whether the attenuated $\triangle \mathrm{ABCH}$ strain was protective against Schu S4 wild type challenge, we infected all of the surviving $\triangle \mathrm{ABCH}$ vaccinated mice (both $10^{3}$ and $10^{6} \mathrm{CFU}$ ) with Schu S4 at 42 days post-vaccination. All the mice succumbed to infection and died by day 13 post-challenge (Fig. 3B). At days 6 and 10 post-challenge, some mice were sacrificed and their organ burdens were determined. The results showed significant bacterial burdens in the liver and spleen of mice 6 days post challenge that increased over a log by 10 days post-challenge (Fig. 3G). 
A.

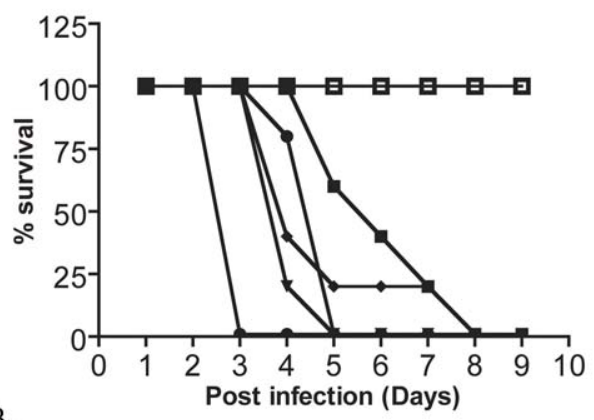

B.

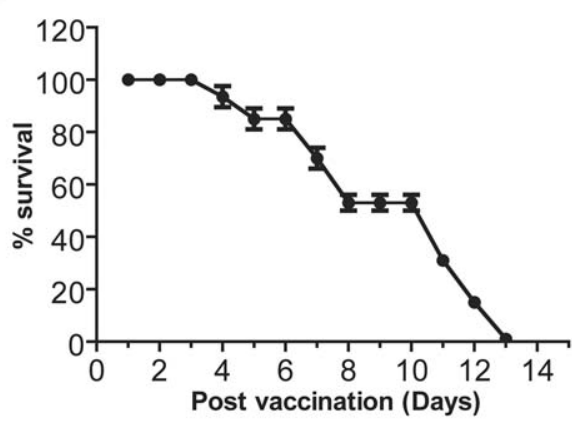

C.

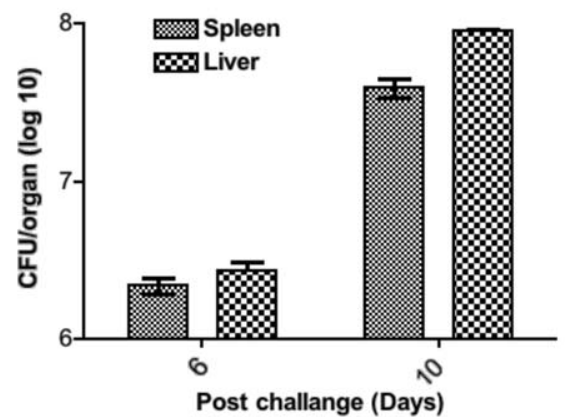

Figure 3. Mouse virulence assays. (A) $B A L B / c$ mice $(N=5)$ were anesthetized and infected with various $F$. tularensis Schu S4 wild type and the acid phosphatase mutants by the intranasal route $\left(3 \times 10^{3}\right.$ CFU of $F$. tularensis). ( $\left.\mathbf{\square}\right), \triangle a c p A(\mathbf{\Delta}), \Delta$ hapA $(\boldsymbol{\nabla}), \mathrm{ACH}(\mathbf{\bullet}), \triangle \mathrm{ABC}(\boldsymbol{\nabla}), \triangle \mathrm{ABCH}(\square)$. (B) Survival of $\triangle A B C H$ vaccinated $B A L B / c$ mice $(N=17)$ challenged with $F$. tularensis Schu $S 4$ wild type 42 days post vaccination. (C) Bacterial load in liver and spleen of $B A L B / c$ mice $(N=3)$ challenged intranasally with the $F$. tularensis Schu S4 wild type strain 42 days post vaccination with the $\triangle A B C H$ strain (both at a dose of $10^{3} \mathrm{CFU}$ ). Mice were sacrificed at various time points post- $F$. tularensis Schu S4 infection to determine the fate of the challenge organisms. doi:10.1371/journal.pone.0056834.g003

\section{TEM analysis of phagosomal escape}

To observe the uptake and trafficking of the Schu S4 wild type and $\triangle \mathrm{ABCH}$ strains, we infected THP-1 macrophages and examined them by transmission electron microscopy at $30 \mathrm{~min}$, $2,6,12,18$ and $24 \mathrm{hrs}$ post infection. We found that at $30 \mathrm{~min}$ post infection, the bacteria that had been engulfed were uniformly enclosed in a membranous vesicle (Fig. 4A). By $2 \mathrm{hrs}$ post infection, $60 \%$ of the wild type and $85 \%$ of $\triangle \mathrm{ABCH}$ strains were still within phagosomes with an intact vacuolar membrane (Fig. $4 \mathrm{~B}$, E). However, at 6 and $12 \mathrm{hrs}$ post infection essentially 100\% of wild type bacteria were found in cytosol (Fig. 4C, E, data not shown). In contrast, $65-$ and $40 \%$ of the $\triangle \mathrm{ABCH}$ bacteria were found in intact phagosome by 6 and $12 \mathrm{hr}$ post infection, respectively (Fig. 4C, E, data not shown). By $18 \mathrm{hrs}$ post infection $11 \%$ of wild type and $47 \%$ of $\triangle \mathrm{ABCH}$ bacteria were within vacuoles with multilayer membranes (data not shown) and similar numbers at $24 \mathrm{hrs}$ post infection (presumed autophagy vacuoles; Fig. 4D, E). These data demonstrate a partial phagosomal escape defect of the $F$. tularensis Schu S4 $\triangle \mathrm{ABCH}$ mutant, likely resulting in the observed killing of this strain within macrophages,

\section{ROS production}

Previous studies demonstrated that deletion of the acid phosphatases in F. novicida resulted in a loss of the ability of the wild type strain to suppress ROS production in human neutrophils and macrophages [49]. To determine whether F. tularensis Schu S4 acid phosphatase mutants also lack this suppressive ability in human phagocytes, we measured the production of ROS in infected human neutrophils and MDMs (60 min time course) using the luminescence probes luminol or lucigenin, respectively.
As observed in our previous study and by others, F. tularensis Schu S4 induced minimal amount of ROS in neutrophils and hMDMs [66] (Fig. 5A and B). However, the formalin killed Schu S4, opsonized zymosan, and PMA stimulate robust ROS production in neutrophils and hMDMs (Fig. 5A and 5B). Phagocytes infected with the $\triangle a c p A$ or $\triangle h a p A$ mutant produced $>12$-fold increased ROS in hMDMs but resulted in no significant change in neutrophil ROS production after $60 \mathrm{~min}$ of infection. However, human neutrophils and hMDMs infected with $\triangle \mathrm{ABCH}$ strain induced a 5- and 56-fold increase in ROS compared to Schu S4 strain, respectively. The $\triangle \mathrm{ABCH}$ strain complemented with pAcpA and/or pHapA restored the ROS suppressive activity of the strain in both neutrophils and hMDMs. Thus, these data suggest that Francisella acid phosphatases, including the truncated HapA, contribute to suppression of ROS production in human phagocytes.

In our previous work, the $F$. novicida $\triangle \mathrm{ABCH}$ mutant was defective in survival within macrophages and neutrophils, and this was demonstrated to be the result of increased ROS production coupled with the dramatic loss in the ability to escape the phagosome. To examine the involvement of ROS in Schu S4 $\triangle \mathrm{ABCH}$ mutant phagocytic cell killing, survival was monitored in BMDM isolated from $\mathrm{C} 57 \mathrm{BL} / 6$ and $\mathrm{p} 47^{\text {phox }}$ congenic knockout mice. The BMDMs isolated from wild type and the $\mathrm{p} 47^{\text {phox-/- }}$ mice were infected with $\mathrm{Schu} \mathrm{S} 4$ wild type, $\Delta a c p A, \Delta h a p A, \triangle \mathrm{ABC}$, $\triangle \mathrm{ACH}$ and $\triangle \mathrm{ABCH}$ strains, and the CFUs were compared at different time points. At $24 \mathrm{hrs}$ post infection, the single and triple mutants examined showed intermediate survival defects in BMDMs of C57BL/6 wild type mice, while the $\triangle \mathrm{ABCH}$ mutant showed a dramatic survival defect (Fig. 6A). In contrast, all strains survived and replicated equally well in BMDM isolated from 
WT

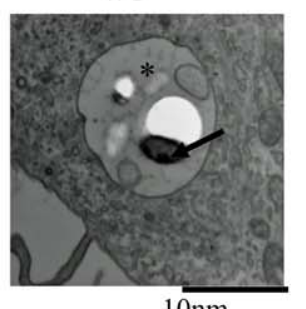

B.

C.

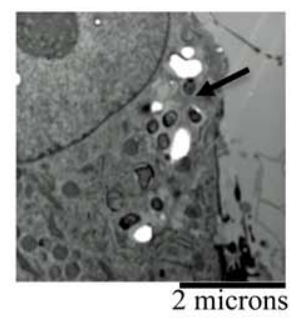

D.

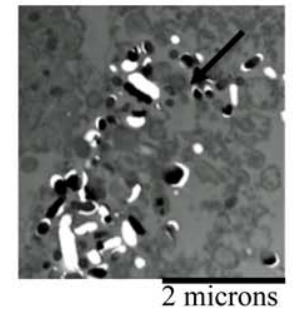

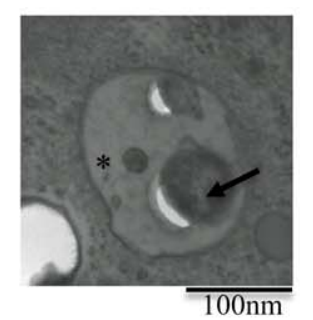

$\mathrm{ABCH}$

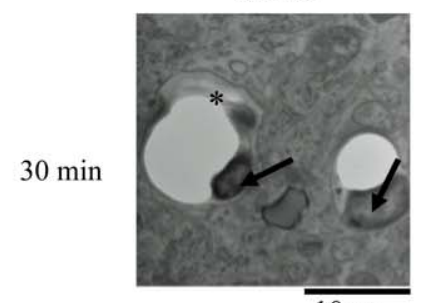

$10 \mathrm{~nm}$

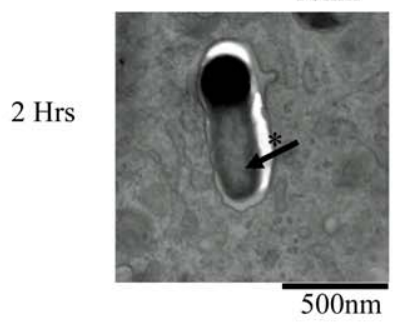

$6 \mathrm{Hrs}$

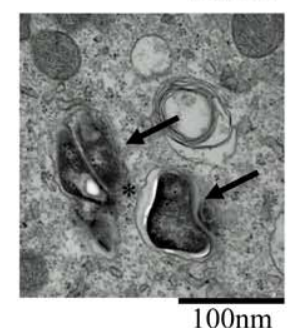

$24 \mathrm{Hrs}$

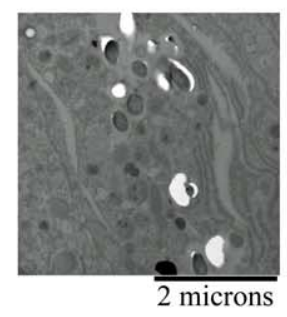

E.

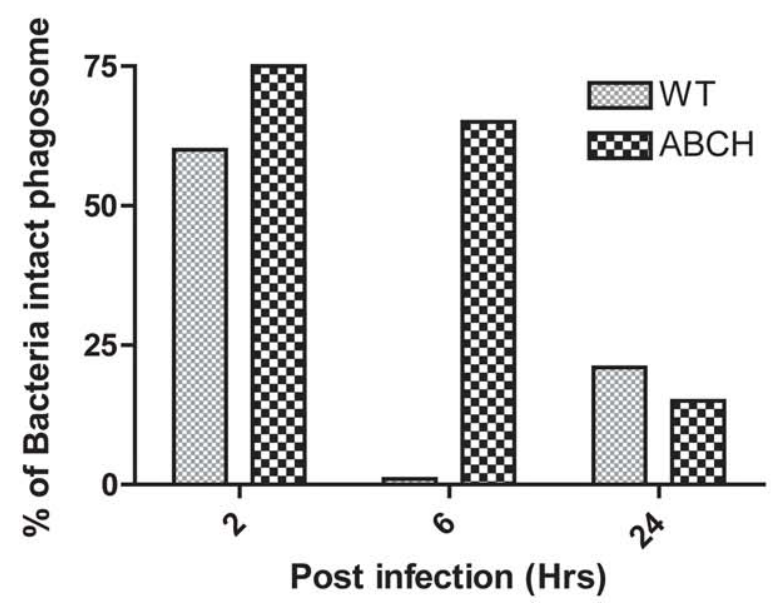

Figure 4. Transmission electron microscopy. Transmission electron microscopy images of PMA-induced THP-1 human macrophagelike cell lines infected with $F$. tularensis Schu S4 (left panel) and $\triangle A B C H$ (right panel) obtained at (A) 30 min, (B) 2 hours, (C) 6 hours, (D) 24 hours post-infection. (E) Quantitative assessment of bacteria within/ outside of phagosomes in a minimum of 300 cross sections/test group ( $\geq 500$ bacteria). An asterisk $\left(^{*}\right)$ represents the double membrane of a vacuole and the arrows point to representative bacteria in the macrophages.

doi:10.1371/journal.pone.0056834.g004
A.

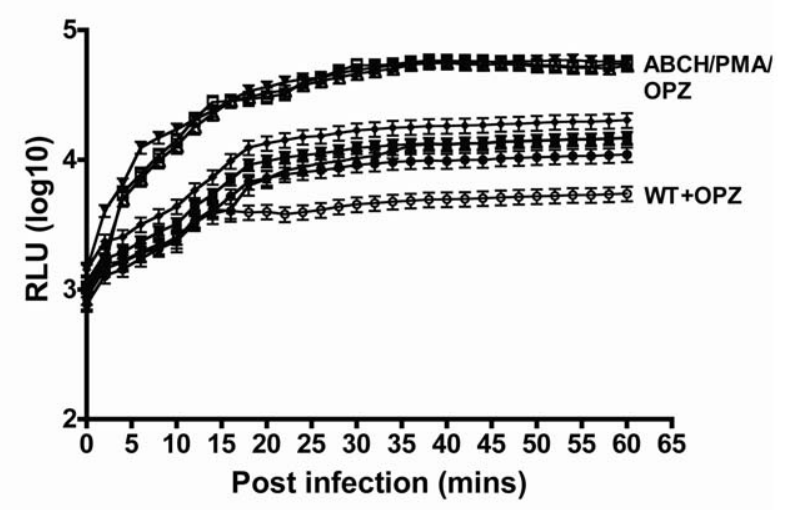

B.

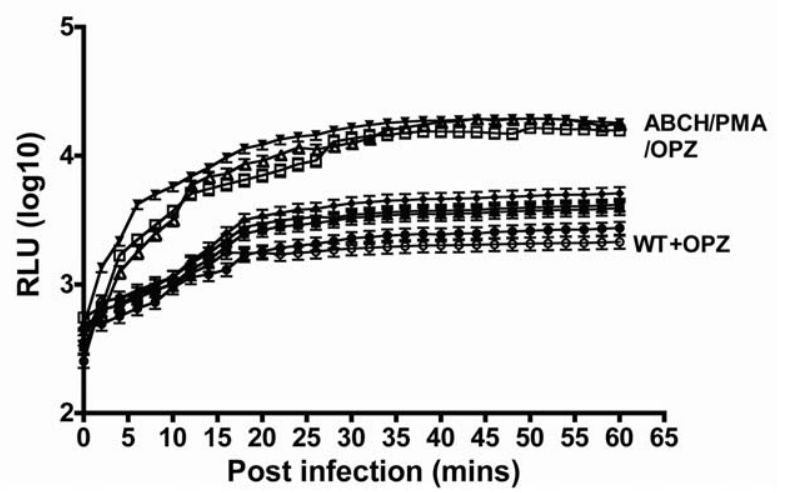

Figure 5. Detection of ROS production in human phagocytes. The luminescence was measured over a 60 min time period in human (A) neutrophils and (B) hMDMs, and the baseline ROS luminescence was determined by measuring the luminescence of control cells treated with medium only. F. tularensis Schu S4 ( $\mathbf{\square}), \triangle \operatorname{acpA}(\mathbf{\Delta}), \Delta$ hapA $(\boldsymbol{\nabla})$, formalin killed $F$. tularensis Schu S4 ( ), F. tularensis Schu S4 and serumopsonized zymosan beads $(\bigcirc), \triangle \mathrm{ABCH}(\square)$, PMA $(\Delta)$, serum-opsonized zymosan $(\nabla)$.

doi:10.1371/journal.pone.0056834.g005

p $47^{\text {phox-/- }}$ mice (Fig. 6B). This suggests a strong correlation of intracellular survival defects in Schu S4 acid phosphatase mutants with NADPH oxidase-mediated ROS production and bacterial killing.

Co-localization of NADPH oxidase components with Francisella in human neutrophils and macrophages

Our previous work in $F$. novicida showed that acid phosphatase mutants co-localized extensively with NADPH oxidase components, as expected by their inability to suppress ROS production within professional phagocytes. Thus, we examined co-localization of Schu S4 wild type, $\triangle a c p A$ and $\triangle \mathrm{ABCH}$ strains with $\mathrm{p} 47^{\text {phox }}$ of human neutrophils and MDMs by confocal microscopy. Representative confocal images of neutrophils with these strains are shown in Fig. 7A. Neutrophils infected with the $\triangle \mathrm{ABCH}$ strain showed an increasing co-localization with $\mathrm{p} 47^{\text {phox }}$ over time that reached its peak $(83 \%)$ at $60 \mathrm{~min}$ post infection (Fig. 7B). The wild type Schu S4 and $\triangle a c p A$ mutants co-localized poorly with $\mathrm{p} 47^{\text {phox }}$ (9 and 13\%, respectively) at $60 \mathrm{~min}$ post infection. Similar, findings were observed in human MDMs infected with Schu S4, $\triangle \mathrm{ABCH}$ and $\triangle a c p A$ mutants. Representative confocal images of infected human MDMs are shown at 60 min post-infection in Fig. 8A. The $\triangle \mathrm{ABCH}$ strain co-localized with $\mathrm{p} 47^{\text {phox }}$ with a maximum of $57 \%$ at $60 \mathrm{~min}$ post-infection, whereas the $\triangle a c p A$ 
A.

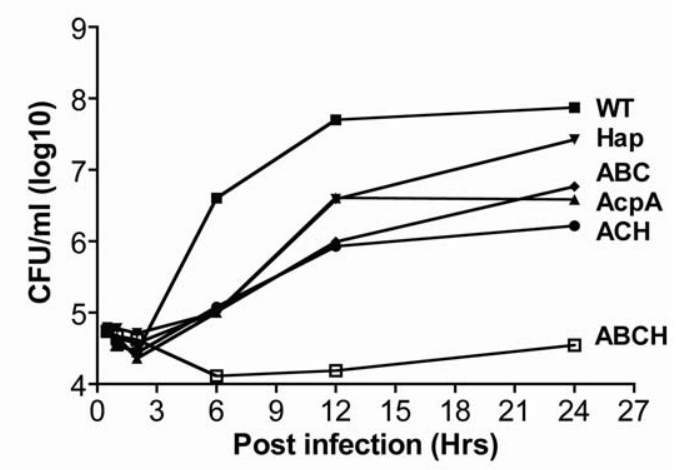

B.

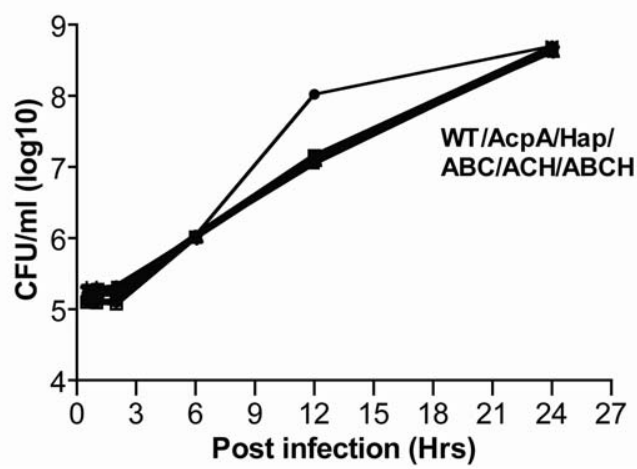

Figure 6. Intramacrophage survival of $F$. tularensis Schu S4 acid phosphatase mutants in BMM from $\mathrm{p} 47^{\text {phox }+/+}$ and $\mathrm{p} 47^{\text {phox-/- }}$ knockout mice. BMM were isolated from (A) $\mathrm{p} 47^{\text {phoxt/+ }}$ wild type C57BL/J mice and (B) p47 $7^{\text {phox-/ }}$ knockout mice C57BL/J infected with $F$. tularensis Schu S4 (ם) or acid phosphatase mutants $\triangle a c p A(\mathbf{\Delta}), \Delta h a p A$ $(\boldsymbol{\nabla}), \triangle \mathrm{ABC}(\bullet), \triangle \mathrm{ACH}(\mathbf{\bullet})$, or $\triangle \mathrm{ABCH}(\square)$ strains. Data are the mean \pm SD of triplicate samples from one representative experiment $(n=2)$. doi:10.1371/journal.pone.0056834.g006

mutant and wild type Schu S4 showed a maximum of $6 \%$ and $4 \%$ co-localization at $60 \mathrm{~min}$ post infection, respectively (Fig. $8 \mathrm{~B}$ ). This suggests that phosphorylation of $\mathrm{p} 47^{\text {phox }}$ was suppressed by Schu S4 wild type strain but the loss of acid phosphatases (multiple but not single) is proposed to allow the $\mathrm{p} 47^{\text {phox }}$ components to phosphorylate and translocate to the membrane.

\section{Increased phosphorylation of NADPH oxidase components upon infection of neutrophils and hMDMs with the $\triangle \mathrm{ABCH}$ mutant strain}

Previous data suggested that the Francisella acid phosphatases may directly or indirectly dephosphorylate NADPH oxidase components $[49,67,68]$. In addition, because phosphorylation of $\mathrm{p} 47^{\text {phox }}$ is required for its recruitment to the phagosome $[69,70]$, the above co-localization data suggests that the $\triangle \mathrm{ABCH}$ strain may lack the ability to dephosphorylate this and other NADPH oxidase components. To determine whether the enhanced ROS stimulation in neutrophils and hMDMs upon infection with $\triangle \mathrm{ABCH}$ mutant strain correlated with increased phosphorylation of NADPH oxidase complex subunits (likely caused by a lack of de-phosphorylation), we examined the phosphorylation of $\mathrm{p} 47^{\text {phox }}$ and $\mathrm{p} 40^{\text {phox }}$ during the course of infection. Neutrophils or hMDMs were infected with Schu $\mathrm{S} 4$ and $\triangle \mathrm{ABCH}$ mutant strains, cells were lysed at different time intervals, and the phosphorylation of $\mathrm{p} 47^{\text {phox }}$ or $\mathrm{p} 40^{\text {phox }}$ was detected by Western blot, using phospho-p $47^{\text {phox }}$ and phospho-p40 phox antibodies. Neutrophils infected with the $\triangle \mathrm{ABCH}$ strain resulted in a rapid increase in phosphorylation of $\mathrm{p} 47^{\text {phox }}$ and $\mathrm{p} 40^{\text {phox }}$ within 5 min of infection compared to the Schu S4 strain (Fig. 9A). Similarly, hMDMs infected with the $\triangle \mathrm{ABCH}$ strain showed an increased phosphorylation of $\mathrm{p} 47^{\text {phox }}$ and $\mathrm{p} 40^{\text {phox }}$ by 15 min of infection (Fig. 9B). These results suggest that in Schu $\mathrm{S} 4$, the NADPH oxidase components are either phosphorylated more effectively or are no longer dephosphorylated in the absence of the Francisella acid phosphatases.

\section{Discussion}

Acid phosphatases are ubiquitous in nature and hydrolyze the phosphoryl groups of phosphomonoesters at an acidic $\mathrm{pH}$ [71]. These enzymes are essential for mobilization of inorganic phosphates and in phospho-relay systems involved in signal transduction pathways in both prokaryotes and eukaryotes. Acid phosphatase enzymes from various pathogens (Leishmania spp, Legionella spp, Bordetella spp and Francisella spp.) are known or suspected to be involved in the virulence by inhibiting reactive oxygen species production in host cells $[54-56,58,72]$.

Our previous study has shown that deletion of four acid phosphatases $(\triangle \mathrm{ABCH})$ in $F$. novicida play a major role in phagosomal escape, intramacrophage survival, virulence in mouse model, induction of ROS production in human phagocytes and co-localization with the NADPH oxidase components of neutrophils and macrophages [23,49]. A study performed by Child et al. illustrated that deletion of AcpA, AcpB and AcpC $(\triangle \mathrm{ABC})$ in $F$. tularensis SchuS4 did not contribute to virulence in mouse and human macrophages [50]. Similar findings were observed in the $\triangle \mathrm{ABC} F$. novicida mutant generated by Mohapatra et al. but the additional deletion of HapA in $F$. novicida $(\triangle \mathrm{ABCH})$ resulted in attenuation of virulence [23]. The Child et al. study did not delete HapA in Schu S4 because it contains a C-terminal disruption by an insertion element, which would eliminate the predicted active site of the produced protein [50]. However, a recent study revealed that the truncated purified HapA protein from $F$. tularensis $\mathrm{Schu} \mathrm{S} 4$ is functional and highly active at low $\mathrm{pH}$ in the presence of magnesium, iron and cobalt [64]. In the present study, we constructed deletion mutants of AcpA, AcpB, AcpC and HapA in the $F$. tularensis Schu $\mathrm{S} 4$ strain to determine if these acid phosphatases contributed to virulence.

In this study, we successfully deleted four acid phosphatases $(a c p A, a c p B, a c p C$ and truncated hapA) in F. tularensis Schu S4 strain. This mutant did not show any defect in growth in MMH broth or abnormal colony morphology on plates. It is clear from acid phosphatase activities measured in the various single, double, triple and quadruple mutant strains that all of the acid phosphatases, including HapA, contributed to the acid phosphatase activity of $F$. tularensis $\mathrm{Schu} \mathrm{S} 4$. Though several combinations of acp deletions eliminate most of the acid phosphatase activity of F. tularensis Schu S4, this does not carry over to complete loss of other phenotypes such as intracellular replication and virulence. The in vivo phenotypes should be viewed independently as they involve documented factors unrelated to in vitro bacterial acid phosphatase activity such as Acp secretion/translocation and in vivo gene induction.

Francisella primarily targets host macrophages for their survival and replication. To examine the affect on virulence of all acid phosphatase mutants, we infected human and mouse macrophages (primary and cell lines) with acid phosphatase mutants. The $\Delta$ hapA strain was defective for survival in various macrophages by $>10$ fold compared to the wild type strain. Similarly, $\triangle \mathrm{ACH}, \triangle \mathrm{ABC}$ 
A.

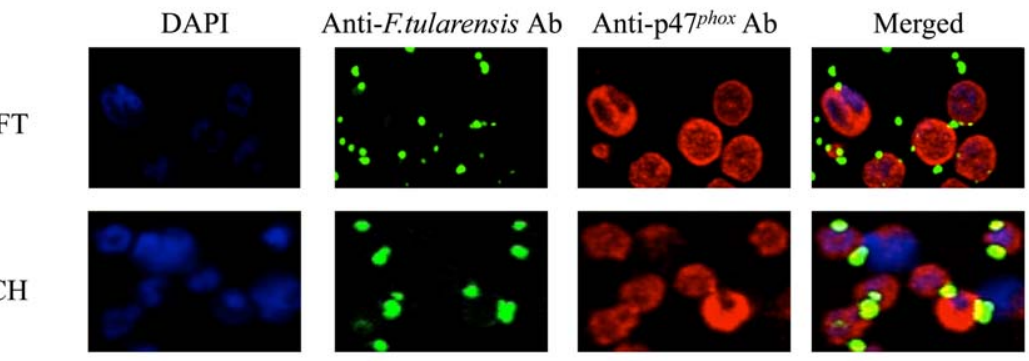

B.

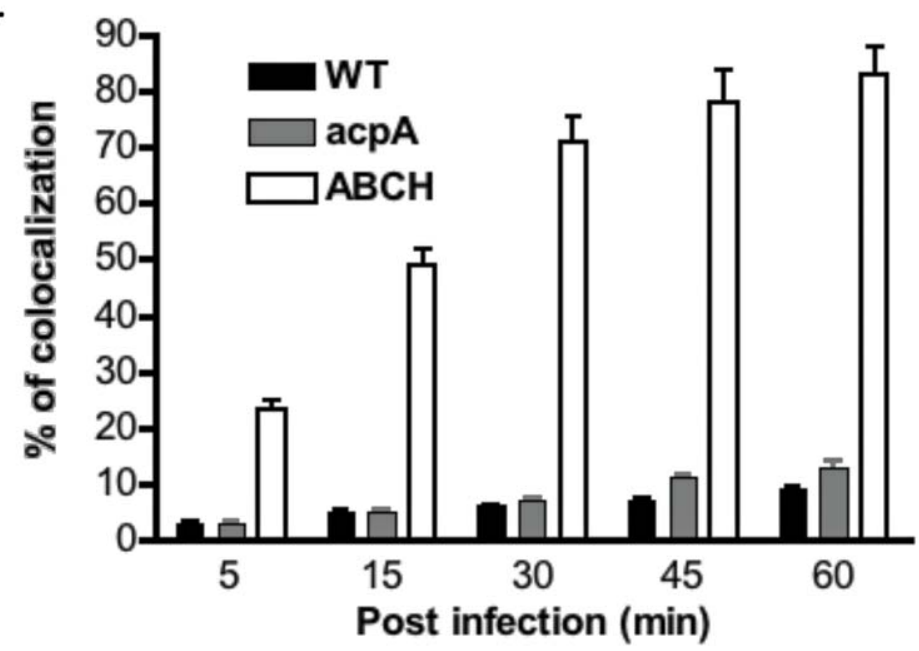

Figure 7. Co-localization of the $F$. tularensis Schu S4 wild type strain and mutant strains with $\mathbf{p 4 7}{ }^{\text {phox }}$ in neutrophils. (A) Co-localization of the F. tularensis Schu S4 wild type and $\triangle \mathrm{ABCH}$ mutant strain with $\mathrm{p} 47^{\text {phox }}$ was determined at $5,15,30,45$ and 60 min post infection in neutrophils. Francisellae were detected following straining with goat anti-mouse Alexa Flour ${ }^{\circledR} 488$ (green color) and p47 ${ }^{\text {phox }}$ was detected following staining with donkey anti-rabbit Alexa Fluor ${ }^{\circledR} 546$ (red color). Representative confocal microscopy images of $F$. tularensis Schu S4 and $\triangle \mathrm{ABCH}$ co-localized with $\mathrm{p} 47^{\text {phox }}$ within neutrophils are shown at $30 \mathrm{~min}$ post infection. The images are representative of 1000 infected cells examined from triplicate cover slips in three independent experiments. (B) Co-localization of the $F$. tularensis Schu S4 wild type (black), $\triangle a c p A$ (grey) and $\triangle \mathrm{ABCH}$ (white) mutant strains with $p 47^{\text {phox }}$ was quantified at $5,15,30,45$ and $60 \mathrm{~min}$ post infection. Analyses were based on examination of 1000 infected cells examined from triplicate cover slips in three independent experiments. The results shown are cumulative data of five experiments (mean \pm SD of triplicate samples in each test group).

doi:10.1371/journal.pone.0056834.g007

and $\triangle \mathrm{ABCH}$ mutants showed $>20-1200$-fold decrease in $\mathrm{CFU}$ numbers at 24 hours post-infection compared to wild type strain. The complementation of $h a p A$ and/or acpA in the $\triangle \mathrm{ABCH}$ mutant partially restored the virulence, clearly indicating that at least these two acid phosphatases of $F$. tularensis $\mathrm{Schu} \mathrm{S} 4$ are active, functional and contribute to Francisella virulence phenotypes.

To further explore the survival and growth of these acid phosphatase mutants in vivo, mice were infected intranasally. We found that the mice infected with single, double or triple acid phosphatase mutants survived longer than wild type strain but died by day $5-8$. This result was similar to our previous result with $F$. novicida and that of Child et al. with $F$. tularensis Schu S4 [50]. However, mice infected with $\triangle \mathrm{ABCH}\left(3 \times 10^{3} \mathrm{CFU} ; 2-3-\operatorname{logs}\right.$ above the $\mathrm{LD}_{50}$ ) were $100 \%$ attenuated, and those infected with $\triangle \mathrm{ABCH}$ at a dose of $10^{6} \mathrm{CFU}$ resulted in $70 \%$ mouse survival at 42 days post-infection. When these vaccinated mice were challenged with the wild type strain, all succumbed by 13 days post-infection. It is unclear why the $\triangle \mathrm{ABCH}$ strain of $F$. novicida was $100 \%$ protective upon challenge while the $F$. tularensis Schu S4 mutant was not. However, the above data strongly support that the additional deletion of the truncated hapA in the $\triangle \mathrm{ABC}$ strain contributes to $F$. tularensis $\mathrm{Schu} \mathrm{S4}$ pathogenesis in vitro and in vivo.

Several studies have been shown that Francisella spp. induce the formation of spacious pseudopod loops for phagocytosis followed by a sequential phagosomal maturation process and escape of Francisella into host cytosol within 2-6 hours post-infection [15,73]. There are likely several virulence factors involved in Francisella phagosomal escape from the Francisella containing vacuole, but the mechanism behind this process has yet to be resolved [19,23,7477]. To better understand the mechanism and view the niche of the $\triangle \mathrm{ABCH}$ strain in host phagocytes, we performed transmission electron microscopy of THP-1 macrophages infected with wild type and acid phosphatase mutants. Our data demonstrated that the wild type strain escaped the phagosome and replicated in the host cytosol by 6 hours post-infection, whereas $\sim 50 \%$ of the $\triangle \mathrm{ABCH}$ mutant were residing in a an intact vacuole at 24 hour post infection. These data suggest that the Francisella acid phosphatases contribute to the kinetics of phagosomal membrane 
A.

FT
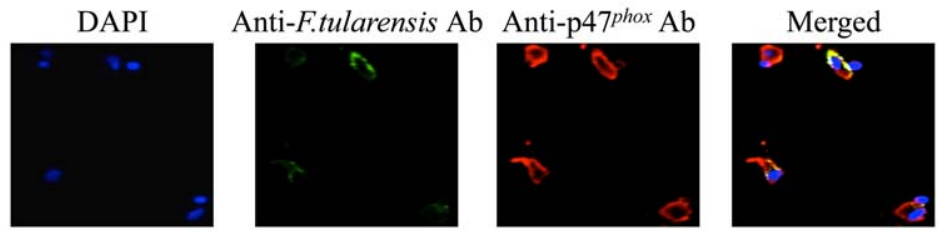

$\triangle \mathrm{ABCH}$
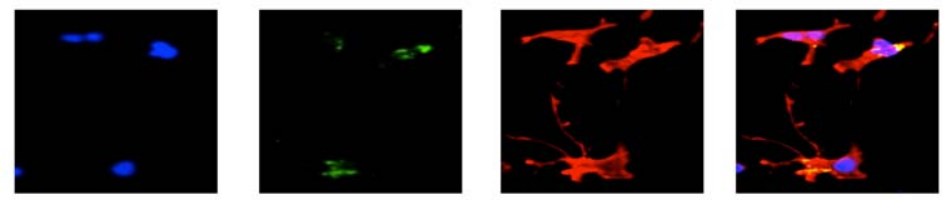

B.

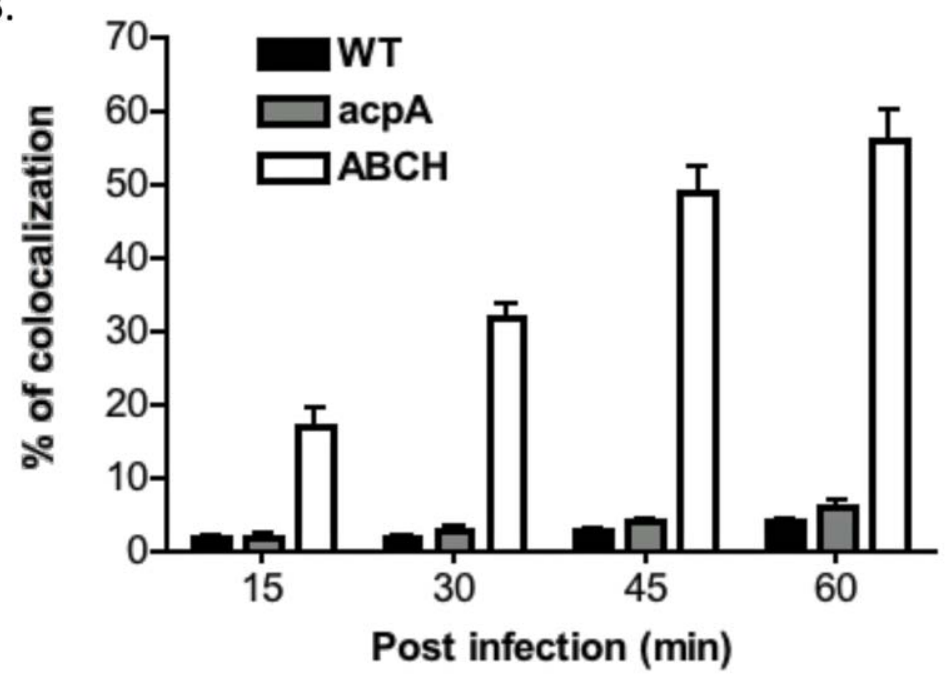

Figure 8. Co-localization of the $F$. tularensis Schu S4 wild type strain and mutant strains with p47 ${ }^{\text {phox }}$ in hMDMs. (A) Co-localization of the wild type and $\triangle \mathrm{ABCH}$ mutant strain with $\mathrm{p} 47^{\text {phox }}$ was determined at 5, 15, 30, 45 and 60 min post infection in neutrophils. F. tularensis Schu S4 strains were detected following straining with goat anti-mouse Alexa Flour ${ }^{\circledR} 488$ (green color) and p47 ${ }^{\text {phox }}$ was detected following staining with donkey anti-rabbit Alexa Fluor ${ }^{\circledR} 546$ (red color). Representative confocal microscopy images of $F$. tularensis Schu S4 and $\triangle A B C H$ co-localized with $\mathrm{p} 47^{\text {phox }}$ within neutrophils are shown at $30 \mathrm{~min}$ post infection. The images are representative of 1000 infected cells examined from triplicate cover slips in three independent experiments. (B) Co-localization of the F. tularensis Schu S4 wild type (black), $\triangle a c p A$ (grey) and $\triangle \mathrm{ABCH}$ (white) mutant strains with gp $91^{\text {phox }}$ was quantified at 5, 15, 30, 45 and 60 min post infection. Analyses were based on examination of 1000 infected cells examined from triplicate cover slips in three independent experiments. The results shown are cumulative data of five experiments (mean \pm SD of triplicate samples in each test group).

doi:10.1371/journal.pone.0056834.g008

disruption, and the inability of the $\triangle \mathrm{ABCH}$ strain to escape from the phagosome and replicate in the cytosol. It is noted that the $F$. novicida $\triangle \mathrm{ABCH}$ mutant had a much greater defect in phagosomal escape, which could be due to the activation or involvement of novel factors present and potentially secreted during $F$. tularensis Schu S4 phagosomal residence.

Our previous studies demonstrated that the collective deletion of four acid phosphatases in F. novicida, unlike the wild type strain, induced the oxidative burst in human neutrophils and monocyte derived macrophages [49]. In $F$. tularensis Schu S4, deletion of these four acid phosphatases also resulted in significant negative effects on virulence-related phenotypes. Furthermore, AcpA is secreted from $F$. tularensis SchuS4 in vitro and in vivo and purified acid phosphatases from Francisella dephosphorylate the NADPH oxidase components $\mathrm{p} 40^{\text {phox }}$ and $\mathrm{p} 47^{\text {phox }}[49,62]$. To determine if the $F$. tularensis Schu $\mathrm{S} 4$ acid phosphatases affect the oxidative burst and to further elucidate the mechanisms behind the attenuation and survival of the $F$. tularensis Schu S4 $\triangle \mathrm{ABCH}$ mutant in vivo and in vitro, we examined ROS induction in infected human neutrophils and MDMs. Our data illustrated that the $\triangle \mathrm{ABCH}$ strain induced a robust oxidative burst and increased ROS production in human MDMs and neutrophils by 5- and 56fold, respectively versus the wild type strain. Additionally we observed that more than $50 \%$ of the $\triangle \mathrm{ABCH}$ strain co-localized with the $\mathrm{p} 47^{\text {phox }} \mathrm{NADPH}$ component in human neutrophils and MDMs at a time point in which $<5 \%$ of the wild type strain similarly co-localized. These data suggest that F. tularensis Schu S4 acid phosphatases are involved in ROS suppression in human phagocytes.

To further understand the necessity and the link between Francisella acid phosphatases with NADPH oxidase components, we isolated the BMDMs from $\mathrm{p} 47^{\text {phox-/- }}$ and wild type mice and infected them with the $F$. tularensis $\mathrm{Schu} \mathrm{S} 4$ and $\triangle \mathrm{ABCH}$ strains. This revealed that the $\triangle \mathrm{ABCH}$ strain was severely defective in survival within BMDMs isolated from wild type mice; however, there was no survival defect observed in BMDMs isolated from in 
A.

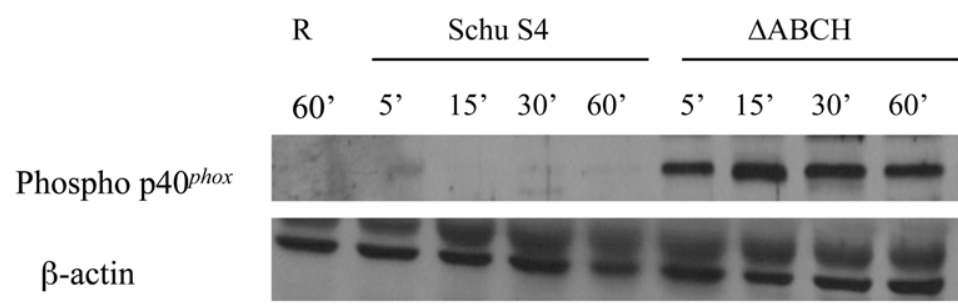

Phospho p47phox

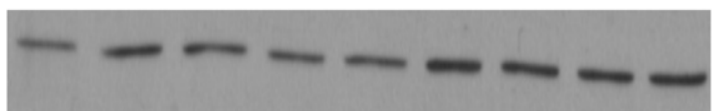

$\beta$-actin

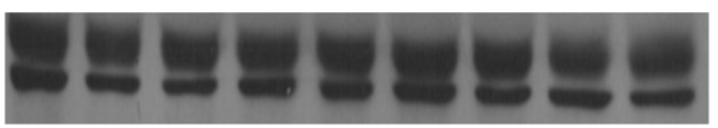

B.

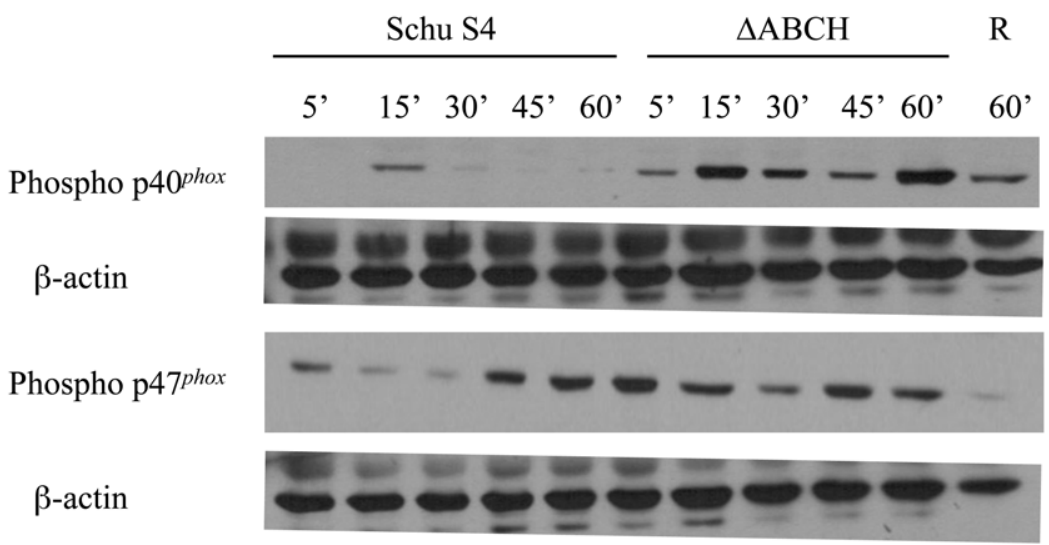

Figure 9. The effect of $F$. tularensis Schu S4 wild type and acp mutants on phosphorylation of p47 ${ }^{\text {phox }}$ and p40 $0^{\text {phox }}$ in human neutrophils and MDMs. (A) Neutrophils or (B) hMDMs were incubated with F. tularensis Schu S4 wild type or $\triangle \mathrm{ABCH}$ strains for the times shown. Lysates were loaded by protein equivalents, separated by SDS-PAGE and analyzed by Western blotting with antibodies specific for phosphorylated $\mathrm{p} 47^{\text {phox }}$ (rabbit anti-Pp47 ${ }^{\text {phox }}$ ) and phosphorylated $\mathrm{p} 40^{\text {phox }}$ (rabbit anti-Pp40 phox). The same membrane was re-probed with $\beta$-actin antibody to verify equal protein loading. Quantification of the ECL signal was measured by using a scanner and densitometry software. A representative Western blot image is shown $(n=7)$.

doi:10.1371/journal.pone.0056834.g009

p47 $7^{\text {phox- } /-}$ at 24 hours post infection. Additionally, Western blot analysis showed that the neutrophils and hMDMs infected with the $\triangle \mathrm{ABCH}$ strain resulted in a marked increase in phosphorylation of $\mathrm{p} 40^{\text {phox }} / \mathrm{p} 47^{\text {phox }}$ as early as 5 minutes post-infection. Our previous study and the present data suggest that, regarding the $\triangle \mathrm{ABCH}$ strain, the relative increase in $\mathrm{p} 47^{\text {phox }}$ and $\mathrm{p} 40^{\text {phox }}$ phosphorylation and association with NADPH oxidase components inside the host phagocytes is a result of the inability to mount an acid phosphatase-mediated dephosphorylation of NADPH oxidase components. This results in an increased ROS response and decreased bacterial survival in phagocytes.

\section{References}

1. Fortier AH, Polsinelli T, Green SJ, Nacy CA (1992) Activation of macrophages for destruction of Francisella tularensis: identification of cytokines, effector cells, and effector molecules. Infect Immun 60: 817-825.

2. Lofgren S, Tarnvik A, Bloom GD, Sjoberg W (1983) Phagocytosis and killing of Francisella tularensis by human polymorphonuclear leukocytes. Infect Immun 39: 715-720.

\section{Acknowledgments}

We thank Dr. Jean Celli, NIAID Rocky Mountain Laboratories, Hamilton, Montana for providing pJC84 plasmid and Dr. Chandan Sen for providing $\mathrm{p} 47^{\text {hox }}$ knockout mice. We thank Larry Schlesinger for his continued assistance and guidance on phagocyte and oxidase experiments.

\section{Author Contributions}

Conceived and designed the experiments: NM SS JG. Performed the experiments: NM SS MR KS. Analyzed the data: NM SS. Contributed reagents/materials/analysis tools: NM SS MR KS. Wrote the paper: NM JG.

3. Lofgren S, Tarnvik A, Carlsson J (1980) Demonstration of opsonizing antibodies to Francisella tularensis by leukocyte chemiluminescence. Infect Immun 29: 329-334.

4. Lofgren S, Tarnvik A, Carlsson J (1980) Influence of complement on the chemiluminescent response of human leukocytes to immune complex. Infect Immun 29: 335-341. 
5. Conlan JW, North RJ (1992) Early pathogenesis of infection in the liver with the facultative intracellular bacteria Listeria monocytogenes, Francisella tularensis, and Salmonella typhimurium involves lysis of infected hepatocytes by leukocytes. Infect Immun 60: 5164-5171.

6. Hall JD, Graven RR, Fuller JR, Pickles RJ, Kawula TH (2007) Francisella tularensis replicates within alveolar type II epithelial cells in vitro and in vivo following inhalation. Infect Immun 75: 1034-1039.

7. Dennis DT, Inglesby TV, Henderson DA, Bartlett JG, Ascher MS, et al. (2001) Tularemia as a biological weapon: medical and public health management. Jama 285: 2763-2773.

8. Feldman KA, Enscore RE, Lathrop SL, Matyas BT, McGuill M, et al. (2001) An outbreak of primary pneumonic tularemia on Martha's Vineyard. N Engl J Med 345: 1601-1606.

9. Tarnvik A, Priebe HS, Grunow R (2004) Tularaemia in Europe: an epidemiological overview. Scand J Infect Dis 36: 350-355.

10. Matyas BT, Nieder HS, Telford SR 3rd (2007) Pneumonic tularemia on Martha's Vineyard: clinical, epidemiologic, and ecological characteristics. Ann N Y Acad Sci 1105: 351-377.

11. Broekhuijsen M, Larsson P, Johansson A, Bystrom M, Eriksson U, et al. (2003) Genome-wide DNA microarray analysis of Francisella tularensis strains demonstrates extensive genetic conservation within the species but identifies regions that are unique to the highly virulent $\mathrm{F}$. tularensis subsp. tularensis. J Clin Microbiol 41: 2924-2931.

12. Elkins KL, Cowley SC, Bosio CM (2007) Innate and adaptive immunity to Francisella. Ann N Y Acad Sci 1105: 284-324.

13. Jones CL, Napier BA, Sampson TR, Llewellyn AC, Schroeder MR, et al. (2012) Subversion of host recognition and defense systems by Francisella spp. Microbiol Mol Biol Rev 76: 383-404.

14. Ben Nasr A, Haithcoat J, Masterson JE, Gunn JS, Eaves-Pyles T, et al. (2006) Critical role for serum opsonins and complement receptors CR3 (CD1lb/ CD18) and CR4 (CD11c/CD18) in phagocytosis of Francisella tularensis by human dendritic cells (DC): uptake of Francisella leads to activation of immature DC and intracellular survival of the bacteria. J Leukoc Biol 80: 774-786.

15. Clemens DL, Lee BY, Horwitz MA (2005) Francisella tularensis enters macrophages via a novel process involving pseudopod loops. Infect Immun 73: 5892-5902.

16. Balagopal A, MacFarlane AS, Mohapatra N, Soni S, Gunn JS, et al. (2006) Characterization of the receptor-ligand pathways important for entry and survival of Francisella tularensis in human macrophages. Infect Immun 74: 5114-5125.

17. Clay CD, Soni S, Gunn JS, Schlesinger LS (2008) Evasion of complementmediated lysis and complement C3 deposition are regulated by Francisella tularensis lipopolysaccharide O antigen. J Immunol 181: 5568-5578.

18. Schulert GS, Allen LA (2006) Differential infection of mononuclear phagocytes by Francisella tularensis: role of the macrophage mannose receptor. J Leukoc Biol 80: 563-571.

19. Chong A, Wehrly TD, Nair V, Fischer ER, Barker JR, et al. (2008) The early phagosomal stage of Francisella tularensis determines optimal phagosomal escape and Francisella pathogenicity island protein expression. Infect Immun 76: 5488-5499.

20. Clemens DL, Lee BY, Horwitz MA (2009) Francisella tularensis phagosomal escape does not require acidification of the phagosome. Infect Immun 77: 17571773 .

21. Santic M, Asare R, Skrobonja I, Jones S, Abu Kwaik Y (2008) Acquisition of the vacuolar ATPase proton pump and phagosome acidification are essential for escape of Francisella tularensis into the macrophage cytosol. Infect Immun 76: 2671-2677.

22. Checroun G, Wehrly TD, Fischer ER, Hayes SF, Celli J (2006) Autophagymediated reentry of Francisella tularensis into the endocytic compartment after cytoplasmic replication. Proc Natl Acad Sci U S A 103: 14578-14583.

23. Mohapatra NP, Soni S, Reilly TJ, Liu J, Klose KE, et al. (2008) Combined deletion of four Francisella novicida acid phosphatases attenuates virulence and macrophage vacuolar escape. Infect Immun 76: 3690-3699.

24. Schwartz JT, Barker JH, Kaufman J, Fayram DC, McCracken JM, et al. (2012) Francisella tularensis inhibits the intrinsic and extrinsic pathways to delay constitutive apoptosis and prolong human neutrophil lifespan. J Immunol 188: 3351-3363.

25. Santic M, Pavokovic G, Jones S, Asare R, Kwaik YA (2010) Regulation of apoptosis and anti-apoptosis signalling by Francisella tularensis. Microbes Infect 12: $126-134$.

26. Lai XH, Sjostedt A (2003) Delineation of the molecular mechanisms of Francisella tularensis-induced apoptosis in murine macrophages. Infect Immun 71: $4642-4646$.

27. Lai XH, Golovliov I, Sjostedt A (2001) Francisella tularensis induces cytopathogenicity and apoptosis in murine macrophages via a mechanism that requires intracellular bacterial multiplication. Infect Immun 69: 4691-4694.

28. Pierini R, Juruj C, Perret M, Jones CL, Mangeot P, et al. (2012) AIM2/ASC triggers caspase-8-dependent apoptosis in Francisella-infected caspase-1-deficient macrophages. Cell Death Differ 19: 1709-1721.

29. Peng K, Broz P, Jones J, Joubert LM, Monack D (2011) Elevated AIM2mediated pyroptosis triggered by hypercytotoxic Francisella mutant strains is attributed to increased intracellular bacteriolysis. Cell Microbiol 13: 1586-1600.
30. Barker JH, McCaffrey RL, Baman NK, Allen LA, Weiss JP, et al. (2009) The role of complement opsonization in interactions between $\mathrm{F}$. tularensis subsp. novicida and human neutrophils. Microbes Infect 11: 762-769.

31. Ludu JS, de Bruin OM, Duplantis BN, Schmerk CL, Chou AY, et al. (2008) The Francisella pathogenicity island protein PdpD is required for full virulence and associates with homologues of the type VI secretion system. J Bacteriol 190: 4584-4595.

32. Santic M, Molmeret M, Barker JR, Klose KE, Dekanic A, et al. (2007) A Francisella tularensis pathogenicity island protein essential for bacterial proliferation within the host cell cytosol. Cell Microbiol 9: 2391-2403.

33. Schmerk CL, Duplantis BN, Wang D, Burke RD, Chou AY, et al. (2009) Characterization of the pathogenicity island protein PdpA and its role in the virulence of Francisella novicida. Microbiology 155: 1489-1497.

34. Tempel R, Lai XH, Crosa L, Kozlowicz B, Heffron F (2006) Attenuated Francisella novicida transposon mutants protect mice against wild-type challenge. Infect Immun 74: 5095-5105.

35. de Bruin OM, Ludu JS, Nano FE (2007) The Francisella pathogenicity island protein IglA localizes to the bacterial cytoplasm and is needed for intracellular growth. BMC Microbiol 7: 1.

36. Baron GS, Nano FE (1998) MglA and MglB are required for the intramacrophage growth of Francisella novicida. Mol Microbiol 29: 247-259.

37. Bell BL, Mohapatra NP, Gunn JS (2010) Regulation of virulence gene transcripts by the Francisella novicida orphan response regulator PmrA: role of phosphorylation and evidence of MglA/SspA interaction. Infect Immun 78: 2189-2198.

38. Brotcke A, Monack DM (2008) Identification of fevR, a novel regulator of virulence gene expression in Francisella novicida. Infect Immun 76: 3473-3480.

39. Brotcke A, Weiss DS, Kim CG, Chain P, Malfatti S, et al. (2006) Identification of MglA-regulated genes reveals novel virulence factors in Francisella tularensis. Infect Immun 74: 6642-6655.

40. Buchan BW, McCaffrey RL, Lindemann SR, Allen LA, Jones BD (2009) Identification of migR, a regulatory element of the Francisella tularensis live vaccine strain iglABCD virulence operon required for normal replication and trafficking in macrophages. Infect Immun 77: 2517-2529.

41. Charity JC, Blalock LT, Costante-Hamm MM, Kasper DL, Dove SL (2009) Small molecule control of virulence gene expression in Francisella tularensis. PLoS Pathog 5: e1000641.

42. Charity JC, Costante-Hamm MM, Balon EL, Boyd DH, Rubin EJ, et al. (2007) Twin RNA polymerase-associated proteins control virulence gene expression in Francisella tularensis. PLoS Pathog 3: e84.

43. Fuller JR, Kijek TM, Taft-Benz S, Kawula TH (2009) Environmental and intracellular regulation of Francisella tularensis ripA. BMC Microbiol 9: 216.

44. Hager AJ, Bolton DL, Pelletier MR, Brittnacher MJ, Gallagher LA, et al. (2006) Type IV pili-mediated secretion modulates Francisella virulence. Mol Microbiol 62: 227-237.

45. Meibom KL, Forslund AL, Kuoppa K, Alkhuder K, Dubail I, et al. (2009) Hfq, a novel pleiotropic regulator of virulence-associated genes in Francisella tularensis. Infect Immun 77: 1866-1880.

46. Mohapatra NP, Soni S, Bell BL, Warren R, Ernst RK, et al. (2007) Identification of an orphan response regulator required for the virulence of Francisella spp. and transcription of pathogenicity island genes. Infect Immun 75: 3305-3314

47. Lauriano CM, Barker JR, Yoon SS, Nano FE, Arulanandam BP, et al. (2004) MglA regulates transcription of virulence factors necessary for Francisella tularensis intraamoebae and intramacrophage survival. Proc Natl Acad Sci U S A 101: 4246-4249.

48. Mohapatra NP, Balagopal A, Soni S, Schlesinger LS, Gunn JS (2007) AcpA is a Francisella acid phosphatase that affects intramacrophage survival and virulence. Infect Immun 75: 390-396.

49. Mohapatra NP, Soni S, Rajaram MV, Dang PM, Reilly TJ, et al. (2010) Francisella acid phosphatases inactivate the NADPH oxidase in human phagocytes. J Immunol 184: 5141-5150.

50. Child R, Wehrly TD, Rockx-Brouwer D, Dorward DW, Celli J (2010) Acid phosphatases do not contribute to the pathogenesis of type A Francisella tularensis. Infect Immun 78: 59-67.

51. Aragon V, Kurtz S, Flieger A, Neumeister B, Cianciotto NP (2000) Secreted enzymatic activities of wild-type and pilD-deficient Legionella pneumophila. Infect Immun 68: 1855-1863.

52. Baca OG, Roman MJ, Glew RH, Christner RF, Buhler JE, et al. (1993) Acid phosphatase activity in Coxiella burnetii: a possible virulence factor. Infect Immun 61: 4232-4239.

53. Burtnick M, Bolton A, Brett P, Watanabe D, Woods D (2001) Identification of the acid phosphatase (acpA) gene homologues in pathogenic and nonpathogenic Burkholderia spp. facilitates TnphoA mutagenesis. Microbiology 147: $111-120$.

54. Jungnitz H, West NP, Walker MJ, Chhatwal GS, Guzman CA (1998) A second two-component regulatory system of Bordetella bronchiseptica required for bacterial resistance to oxidative stress, production of acid phosphatase, and in vivo persistence. Infect Immun 66: 4640-4650.

55. Reilly TJ, Baron GS, Nano FE, Kuhlenschmidt MS (1996) Characterization and sequencing of a respiratory burst-inhibiting acid phosphatase from Francisella tularensis. J Biol Chem 271: 10973-10983.

56. Saha AK, Dowling JN, LaMarco KL, Das S, Remaley AT, et al. (1985) Properties of an acid phosphatase from Legionella micdadei which blocks 
superoxide anion production by human neutrophils. Arch Biochem Biophys 243: $150-160$.

57. Saleh MT, Belisle JT (2000) Secretion of an acid phosphatase (SapM) by Mycobacterium tuberculosis that is similar to eukaryotic acid phosphatases. J Bacteriol 182: 6850-6853.

58. Remaley AT, Das S, Campbell PI, LaRocca GM, Pope MT, et al. (1985) Characterization of Leishmania donovani acid phosphatases. J Biol Chem 260: 880-886.

59. Twine SM, Shen H, Kelly JF, Chen W, Sjostedt A, et al. (2006) Virulence comparison in mice of distinct isolates of type A Francisella tularensis. Microb Pathog 40: 133-138.

60. Pierson T, Matrakas D, Taylor YU, Manyam G, Morozov VN, et al. (2011) Proteomic Characterization and Functional Analysis of Outer Membrane Vesicles of Francisella novicida Suggests Possible Role in Virulence and Use as a Vaccine. J Proteome Res 10: 954-967.

61. Konecna K, Hernychova L, Reichelova M, Lenco J, Klimentova J, et al. (2010) Comparative proteomic profiling of culture filtrate proteins of less and highly virulent Francisella tularensis strains. Proteomics 10: 4501-4511.

62. Dai S, Mohapatra NP, Schlesinger LS, Gunn JS (2012) The acid phosphatase AcpA is secreted in vitro and in macrophages by Francisella spp. Infect Immun 80: 1088-1097.

63. Wehrly TD, Chong A, Virtaneva K, Sturdevant DE, Child R, et al. (2009) Intracellular biology and virulence determinants of Francisella tularensis revealed by transcriptional profiling inside macrophages. Cell Microbiol 11: $1128-1150$.

64. McRae S, Pagliai FA, Mohapatra NP, Gener A, Mahmou AS, et al. (2009) Inhibition of AcpA phosphatase activity with ascorbate attenuates Francisella tularensis intramacrophage survival. J Biol Chem 285: 5171-5177.

65. Rajaram MV, Ganesan LP, Parsa KV, Butchar JP, Gunn JS, et al. (2006) Akt/ Protein kinase B modulates macrophage inflammatory response to Francisella infection and confers a survival advantage in mice. J Immunol 177: 6317-6324.

66. McCaffrey RL, Schwartz JT, Lindemann SR, Moreland JG, Buchan BW, et al. (2010) Multiple mechanisms of NADPH oxidase inhibition by type A and type B Francisella tularensis. J Leukoc Biol 88: 791-805.

67. Geier H, Celli J (2011) Phagocytic receptors dictate phagosomal escape and intracellular proliferation of Francisella tularensis. Infect Immun.
68. Kuolee R, Harris G, Conlan JW, Chen W (2011) Role of neutrophils and NADPH phagocyte oxidase in host defense against respiratory infection with virulent Francisella tularensis in mice. Microbes Infect.

69. Uhlinger DJ, Perry DK (1992) A carboxy-terminal peptide from p47-phox is a substrate for phosphorylation by protein kinase $\mathrm{C}$ and by a neutrophil protein kinase. Biochem Biophys Res Commun 187: 940-948.

70. Heyworth PG, Curnutte JT, Nauseef WM, Volpp BD, Pearson DW, et al. (1991) Neutrophil nicotinamide adenine dinucleotide phosphate oxidase assembly. Translocation of $\mathrm{p} 47$-phox and $\mathrm{p} 67$-phox requires interaction between $\mathrm{p} 47$-phox and cytochrome b558. J Clin Invest 87: 352-356.

71. Vincent JB, Crowder MW, Averill BA (1992) Hydrolysis of phosphate monoesters: a biological problem with multiple chemical solutions. Trends Biochem Sci 17: 105-110.

72. Remaley AT, Glew RH, Kuhns DB, Basford RE, Waggoner AS, et al. (1985) Leishmania donovani: surface membrane acid phosphatase blocks neutrophil oxidative metabolite production. Exp Parasitol 60: 331-341.

73. Santic M, Molmeret M, Abu Kwaik Y (2005) Modulation of biogenesis of the Francisella tularensis subsp. novicida-containing phagosome in quiescent human macrophages and its maturation into a phagolysosome upon activation by IFNgamma. Cell Microbiol 7: 957-967.

74. Barker JR, Chong A, Wehrly TD, Yu JJ, Rodriguez SA, et al. (2009) The Francisella tularensis pathogenicity island encodes a secretion system that is required for phagosome escape and virulence. Mol Microbiol 74: 1459-1470.

75. Golovliov I, Baranov V, Krocova Z, Kovarova H, Sjostedt A (2003) An attenuated strain of the facultative intracellular bacterium Francisella tularensis can escape the phagosome of monocytic cells. Infect Immun 71: 5940-5950.

76. Santic M, Molmeret M, Klose KE, Jones S, Kwaik YA (2005) The Francisella tularensis pathogenicity island protein $\mathrm{IglC}$ and its regulator MglA are essential for modulating phagosome biogenesis and subsequent bacterial escape into the cytoplasm. Cell Microbiol 7: 969-979.

77. Fuller JR, Craven RR, Hall JD, Kijek TM, Taft-Benz S, et al. (2008) RipA, a cytoplasmic membrane protein conserved among Francisella species, is required for intracellular survival. Infect Immun 76: 4934-4943.

78. Maier TM, Havig A, Casey M, Nano FE, Frank DW, et al. (2004) Construction and characterization of a highly efficient Francisella shuttle plasmid. Appl Environ Microbiol 70: 7511-7519. 